K. S. Frepberger

\title{
Sakrale Kommunikationsräume auf dem Forum Romanum
}

\section{Einleitung}

Im nordwestlichen Bereich des Forum Romanum zwischen der Curia im Westen und dem Tempel des Antoninus Pius und der Faustina im Osten befand sich der luxuriöse Bau der Basilica Aemilia, dessen Hauptfassade, die Südfront, mit ihrer Längsseite zum Forumsplatz ausgerichtet war und an den Nordrand der Via Sacra angrenzte (Abb. I). ${ }^{\mathrm{I}}$ Nicht nur die Basilica war durch ihre Größe und aufwendige Ausstattung prestigeträchtig, sondern auch der Ort selbst, zumal dieser mit Erinnerungen an die Gründungsgeschichte Roms verbunden war.

Nach der mythologischen Überlieferung war der Abschnitt der Via Sacra vor der Basilica Aemilia Schauplatz des Kampfes zwischen den Sabinern und Römern, den die beiden Kontrahenten, die Könige Romulus und Titus Tatius, mit einem Waffenstillstand vor dem Heiligtum der Venus Cloacina beendeten (Abb. 2). ${ }^{2}$ Dieses Sacellum und andere kleine Kultorte im zentralen Forumsbereich waren keine isolierten Stätten, sondern sie verwiesen in ihrer Gesamtheit auf die Geschichte der Stadt Rom und deren heiligen Charakter.

Vor dem Hintergrund dieser Situation sind traditionelle Kultbauten im Umfeld der Basilica Aemilia unter dem Gesichtspunkt zu betrachten, welche Bedeutung sie hatten und in welcher inhaltlichen Beziehung sie zueinander standen. Mit dieser Aufgabe ist die Absicht verbunden, ein neues Verständnis für die sakralen Kommunikationsräume auf dem Forum Romanum zu gewinnen.

\section{Das Atrium Regium}

Der Überlieferung zufolge stand im Bereich der Basilica Aemilia das Atrium Regium, das in der Königszeit die „offizielle“ Residenz des Königs war und als pars publica fungierte. 3 Der Gründer des Bauwerks war der mythische König Numa Pompilius, der in diesem Gebäude seinen Amtssitz hatte. ${ }^{4}$ In diesem verkehrte der König mit seinen Untergebenen, wobei politische, wirtschaftliche, soziale und juristische Angelegenheiten ausgehandelt wurden.

I Ertel u. Freyberger (2007) I09-I42; Freyberger, Ertel, Lipps u. Bitterer (2007) 493-452; Freyberger (2009b) I64-I7I; Freyberger (2010) I6-57.

2 Platner u. Ashby (I929) I28; Coarelli (I983) 83-89; Coarelli (г993) 290f.; Köb (2000) 36-40.

3 Gaggiotti (I985) 58.

4 Cass. Dio I, Frgm. 6 (2). 

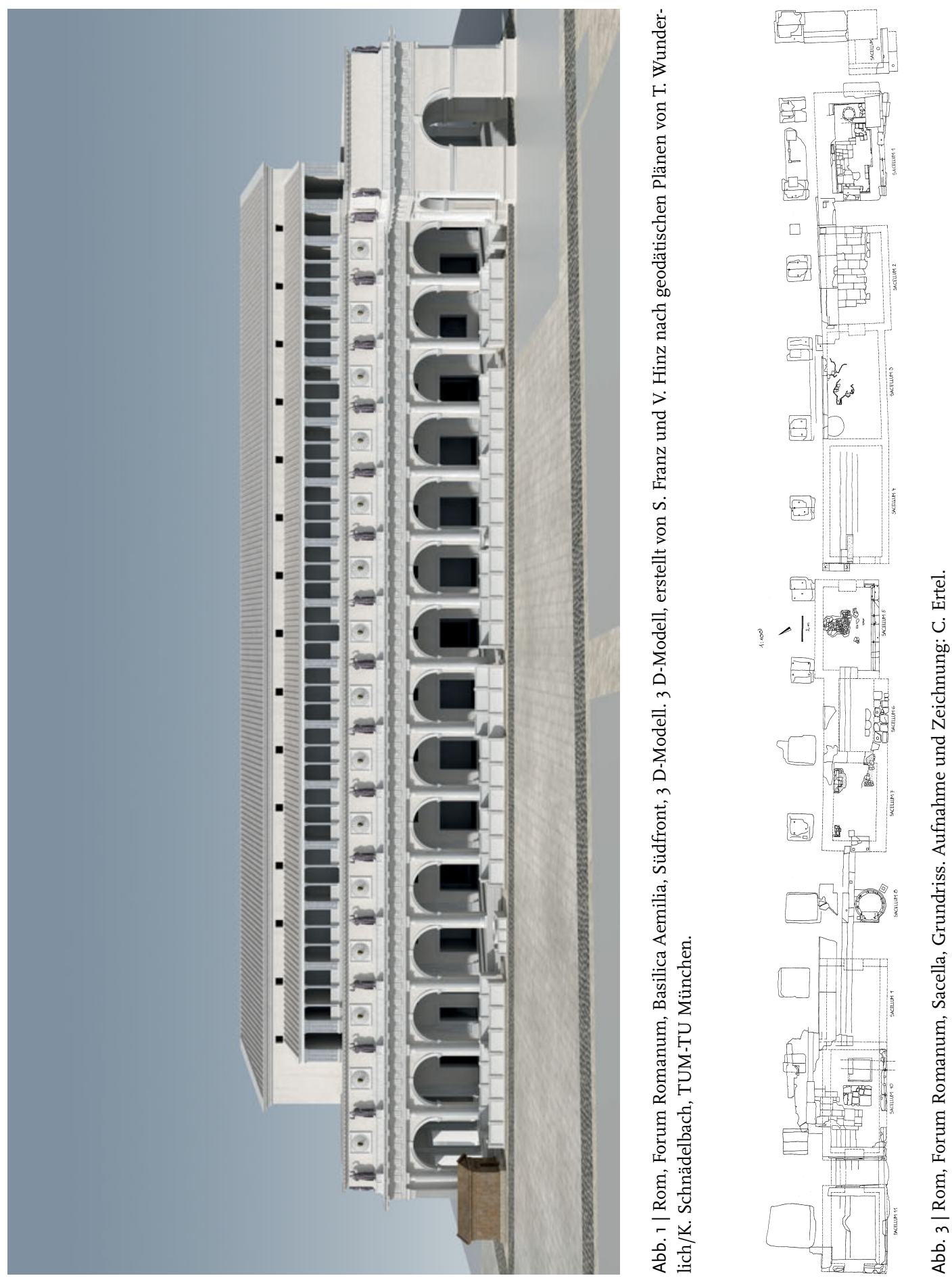
Laut den Angaben von Cassius Dio verwaltete der König in diesem Bauwerk die Güter der Stadt, sprach Recht und übte rituelle Handlungen bei den an der Via Sacra liegenden Archeia aus.5 Aus diesen Nachrichten ergeben sich Aufschlüsse für den Urbau der Basilica Aemilia. Die Lagerung von Gütern und die Rechtssprechung sind Funktionen, die an diesen Ort gebunden waren und sich in der Basilica Aemilia über einen langen Zeitraum fortsetzten.

Die Platzwahl für den späteren Bau der Basilica Aemilia hat noch eine andere Bedeutung, die weniger von konkreter, sondern eher symbolischer Bedeutung war. Nach dem ideologischen Verständnis der Aemilier war ihr großer Ahnherr Numa Pompilius, der als Gründer des Atrium Regium gilt. Das genealogische Verhältnis mit Numa kommt vor allem in der Dualität des Atrium Regium und der Basilica Aemilia lebhaft zur Geltung. Vor diesem Hintergrund gewinnt das Bauwerk der Aemilier eine enorme politische Dimension, die durch die Lage und luxuriöse Formgebung des Gebäudes unterstrichen wird. Anstelle des Königs sind es aber nun die römischen Bürger der Republik, vertreten durch die gentes, die in der Basilica wirtschaftlich, politisch und juristisch agieren. Auf diese Weise ist die Basilica Aemilia nicht nur die „republikanische“ Fortsetzung des Atrium Regium, sondern sie übernimmt auch dessen Funktionen. ${ }^{6}$

\section{Die Sacella}

Eine Identifizierung der von Cass. Dio überlieferten Archeia ermöglichen die unlängst freigelegten Fundamente und Mauern zwischen dem Nordrand der Via Sacra und der Südfront der Portiken vor der Basilika Aemilia (Abb. 3). ${ }^{7}$ Es handelt sich dabei um elf kleine Heiligtümer, von denen nur das Heiligtum der Venus Cloacina bekannt ist. Die mit einer Brüstung umfassten Bezirke von etwa $6 \mathrm{~m}$ bis $8 \mathrm{~m}$ Länge und $4 \mathrm{~m}$ Breite sind mit ihrer Längsseite zum Forumsplatz ausgerichtet und hatten ihren Eingang auf einer der Schmalseiten, von dem Stufen in den tiefer gelegenen Bezirk hinabführten. Aller Wahrscheinlichkeit nach sind diese Sacella mit den von Cass. Dio überlieferten Archeia zu identifizieren,

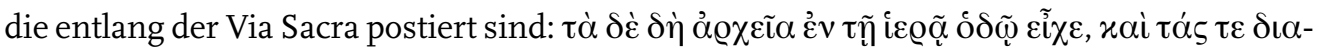

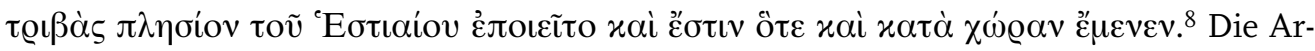
cheia lagen ursprünglich vor der Südseite des Atrium Regium und sind demzufolge topo-

\section{S. o. Anm. 4 .}

6 Treffend beschreibt Gaggiotti (I985) 66 die politische Bedeutung des Bauwerks: „Die Basilica, die aus dem Atrium Regium hervorging, nahm inzwischen den Wert einer Reliquie ein“.

7 Diese Strukturen ließ der Verfasser im Rahmen der Untersuchungen zur Basilica Aemilia im Jahr 2008 freilegen und dokumentieren. Die Auswertung wird in der Endpublikation veröffentlicht: C. Ertel, K. S. Freyberger, K. Tacke u. T. Bitterer: Die Basilica Aemilia auf dem Forum Romanum in Rom: Ein öffentlicher Luxusbau für Handel und Justiz (In Vorbereitung für den Druck; erscheint in den Sonderschriften des DAI-Rom).

8 Cass. Dio I, frg. 6 (2). 


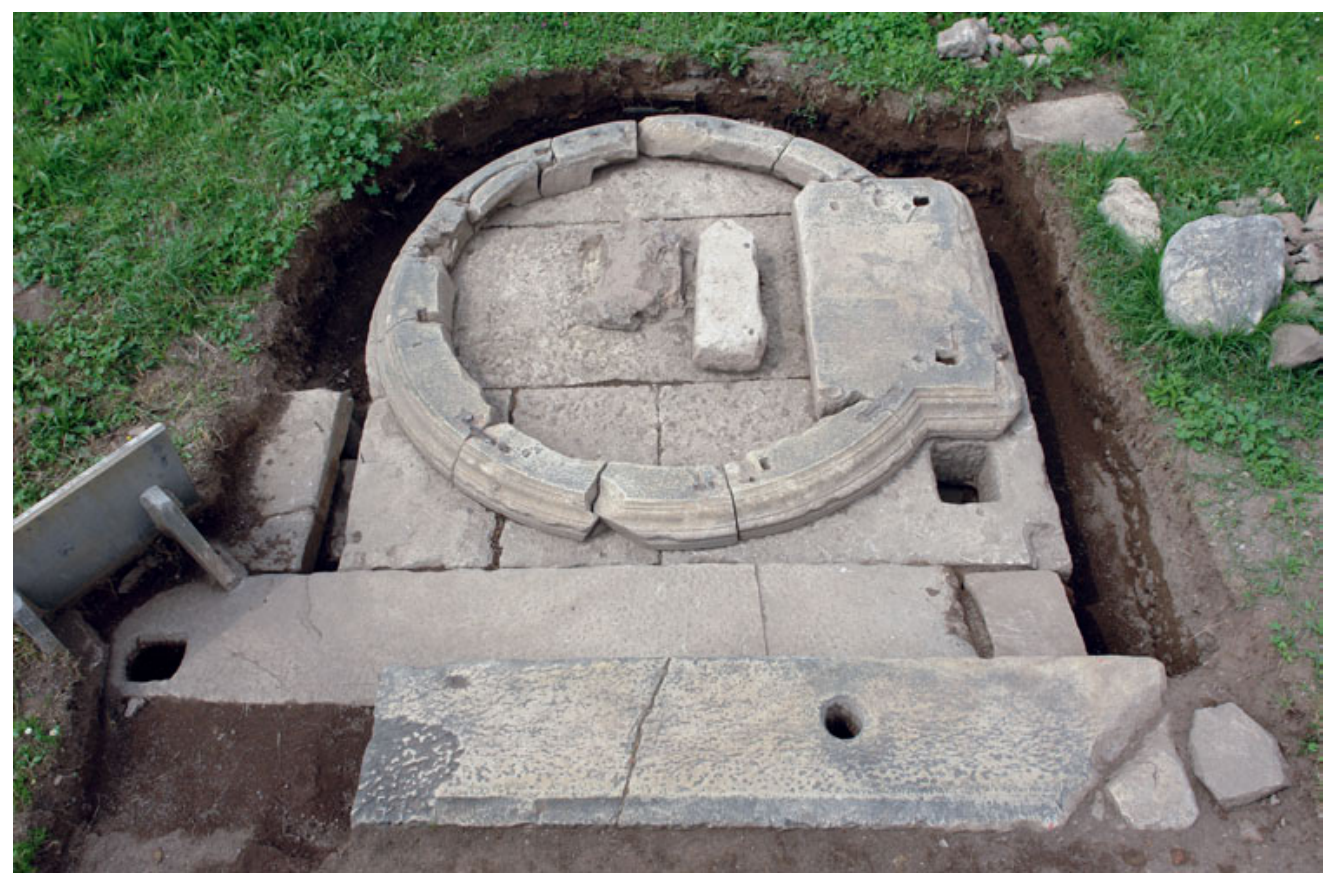

Abb. 2 | Rom, Forum Romanum, Sacellum der Venus Cloacina. Foto H. Behrens, DAI-Rom dig. 2007.2743.

grafisch von dem Komplex des Hestiaion und der Regia zu unterscheiden.9 Aufgrund ihrer Lage an der Via Sacra haben die Sacella einen Grenzcharakter, zumal dieser Weg nach der mythologischen Überlieferung die Grenze zwischen den Gemeinwesen der Römer und Sabiner war (Vgl. Abb. I).

\subsection{Puteal Libonis}

An der Südostecke der Portiken der Basilica Aemilia befindet sich ein Sacellum, das vor der östlichen Schmalseite die Fundamente einer Brunnenfassung zeigt (Abb. 4). ${ }^{\text {.० }}$ Nach seinem Aufbau und den topografischen Angaben antiker Autoren zu urteilen, könnte es sich bei diesem Sacellum um das bekannte Puteal Libonis handeln, das als Sitz des Tribunal Praetoris fungierte. ${ }^{\text {II }}$ Denare des L. Scribonius Libo aus dem Jahr 62 v. Chr. zeigen die mit

9 Gaggiotti (I985) 59. Plutarch (Num. I4, I) bezeichnet die Regia, das Wohnhaus des Königs als $\pi \lambda \eta \sigma i ́ o v$.

Io Freyberger (2009a) I5 Abb. 3a.b; 45-47.

II Platner u. Ashby (I929) 434; 607; Nash II (I962) 259-26ı Abb. IoII; Welin (I953) I-74; Coarelli (I985) I66-I89; Chioffi (I999) I7I-I73. 
Abb. 4 | Rom, Forum Romanum, Puteal Libonis, Mauern und Fundamente. Foto H. Behrens, DAI-Rom dig. 2008.350I.

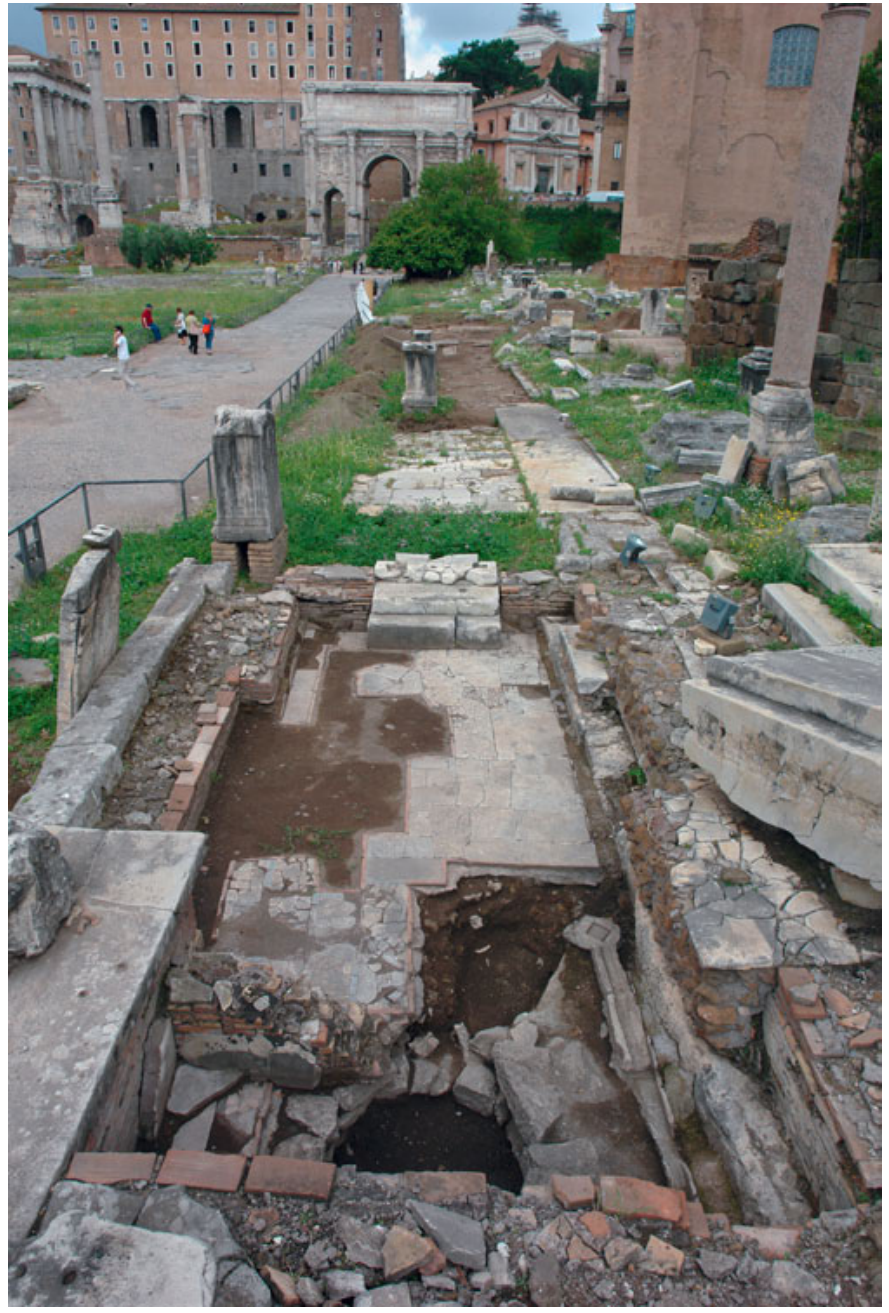

Reliefs geschmückte Außenwand des Brunnens. ${ }^{\mathrm{I2}}$ Dargestellt sind die Attribute des Vulkan: ein Hammer, ein Paar Zangen, ein Amboss und die mit Lorbeer geschmückte Kappe. Die Verbindung des Silberschmiedhandwerks mit Münzen kommt anschaulich auf einem Silberdenar des T. Carisius zur Geltung, dessen Avers den Kopf der Iuno Moneta und dessen Revers die Attribute des Vulkan wiedergeben. ${ }^{13}$ Bei einem Rundaltar der Pietas aus Veji handelt es sich vermutlich um eine Replik des Puteal Libonis, der sich heute in den Vatika-

I2 Fuchs (I969) 23-26 Taf. 3,33-36; Coarelli (1985) I67 Abb. 27; Freyberger (2009a) 46 Abb. 28.

I3 Balbi de Caro (I989) I7f. Abb. II. 
nischen Museen in Rom befindet. ${ }^{\mathrm{I} 4}$ Um die Wand verlaufen große Fruchtgirlanden, die an Leiern, dem Attribut des Apollon, hängen. Welche Bedeutung dieser Gott in der Verbindung mit dem Puteal hatte, ist bis heute nicht bekannt. Nach der Meinung von Welin kann der Grund für diesen Sachverhalt sein, dass das Puteal erst nach der Befragung der Sibyllinischen Bücher errichtet wurde. ${ }^{15}$ Die Verknüpfung mit Apollon könnte aber auch in Zusammenhang mit der Funktion der Basilica als Gerichtsstätte stehen, indem der Gott als Schlichter oder Richter angesehen wird. In ihrer Bedeutung unmissverständlich sind aber die Attribute des Vulkan, die auf die Funktion der Tabernen als Verkaufstätte von Silberwaren anspielen. Das Puteal Libonis ist eng an die legislative und juristische Funktion gebunden. Es markiert den Sitz des Tribunal Praetoris, das der Volkstribun Scribonius Libo im Jahr I49 v. Chr. vom Comitium zum Forum verlegen ließ.

Umstritten ist die Lokalisierung des Puteals, obwohl die Angaben der antiken Autoren zu dessen Position ziemlich genau sind. Von entscheidender Bedeutung ist die Nachricht von Festus, nach der das Puteal vor den atria lag: <Scribonianum ap>pellatur ante[a] atria. ${ }^{\mathrm{I} 6}$ Die Nennung ante atria verweist auf das Atrium Regium und damit verbunden auf den Bereich der späteren Basilica Aemilia. Noch präziser sind die Angaben des Persius:I7 laut diesen versammelten sich die Geldverleiher, die Feneratores, unweit des Brunnens des Scribonius Libo, der in der Porticus Iulia nahe beim Fornix Fabianus stand. Der Brunnen als Versammlungsort dieser Leute lässt darauf schließen, dass er in unmittelbarer Nähe des Ianus medius lag, der als Stätte der Zinsverleiher fungierte. ${ }^{18}$ Eine weitere topografische Angabe ist der Fornix Fabianus, ${ }^{19}$ der sich iuxta Regiam, ${ }^{20}$ prope Vestam ${ }^{2 \mathrm{I}}$ und ante sacram viam inter templum Faustinae ac Vestam ${ }^{22}$ befand. Aufgrund dieser Angaben ist der Bogen nicht südlich, sondern nördlich des Tempels des Divus Iulius zu lokalisieren. ${ }^{23}$ Aus letzterem Bereich stammt das Fragment eines dorischen Frieses aus Travertin, das zu dem Bogen gehörte und damit dessen Lage an dieser Stelle bestätigt. Als dritter Punkt ist die Porticus Iulia nahe beim Fornix Fabianus genannt, die sich demzufolge im nördlichen Bereich des Forums befand und mit großer Wahrscheinlichkeit mit den Portiken vor den Läden der

\footnotetext{
I4 Fuchs (I969) I24f. Taf. I5, I48-I5I; Freyberger (2009a) 46 Abb. 29a-d.

I5 Welin (I953) 34 .

I6 Festus 448 L. Coarelli (I985) I69.

I7 Pers. 4,49.

I8 Cic. off. 2,87; Cic. Phil. 6,5,I5.

i9 Nash I (I96I) 398-400; Welin (I953) 37-46; Platner u. Ashby (I929) 2IIf.; Coarelli (I985) I7I-I80; Chioffi (I995) 264-266; Chioffi (I996) 26-36.

20 Pseudasc. ad Cic. Verr. I 7,I9.

2I Pers. 4,49.

22 SHA Salon. I.

23 Zur Diskussion über die Lokalisierung des Fornix Fabianus: Coarelli (I985) I72 Anm. 3I.32; Carnabuci (I99I) 327 lokalisiert den Bogen zu Recht in der Zone zwischen der Basilica Aemilia, dem Tempel des Antoninus Pius, der Regia und dem Tempel des Divus Iulius. Wahrscheinlich stand er ein wenig weiter östlich des Bogens der Fasti. Nach den jüngsten Untersuchungen des Autors stand der Bogen in Höhe der Ostante des Tempels des Antoninus Pius und der Faustina auf der Via Sacra.
} 
Basilica Aemilia zu identifizieren ist. Zu Lebzeiten der Stiefsöhne des Augustus hieß sie Porticus Gai et Luci und erhielt ihren ursprünglichen Namen nach dem frühen Tod von Gaius und Lucius Caesar zurück. ${ }^{24}$ Ein analoger Vorgang ist auch für die Basilica Iulia zu postulieren. Nach den überlieferten topografischen Gegebenheiten zu urteilen, befand sich das Puteal Libonis im südöstlichen Bereich der Portiken vor der Basilica Aemilia. Zieht man die Form und Bedeutung dieser Kultstätte sowie die topographischen Angaben antiker Autoren in Betracht, so ist das Sacellum Nr. I mit dem Puteal Libonis gleichzusetzen (Abb. I.3.4).25 Die Lokalisierung dieses Ortes als Sitz des Tribunal Praetoris wird durch weitere Indikatoren gestützt: Unweit dieser Stelle befand sich in der Taberne 9 die bekannte Wasseruhr, die den Zeitpunkt des Beginns der Gerichtsverhandlungen anzeigte. ${ }^{26}$

\subsection{Das Heiligtum des lanus Geminus}

Das Sacellum Nr. II an der Südwestecke der Basilica Aemilia ist allem Anschein nach mit dem Heiligtum des Ianus Geminus zu identifizieren (Abb. I.3). ${ }^{27}$ Es handelt sich um jenen Bau, der heute von den Kustoden der Soprintendenz als Wärterhäuschen benutzt wird. ${ }^{28}$ Wie die Untersuchungen von C. Ertel ergaben, besaß die Kultstätte zwei sich gegenüberliegende Eingänge auf der Nord- und Südseite. Neben diesem Befund, der das zuverlässigste Kriterium für die Identifizierung des Gebäudes als ein Heiligtum des Ianus liefert, stimmt dessen Lage mit den topografischen Angaben antiker Autoren genau überein. Nach Seneca liegt das Heiligtum auf dem Forum. ${ }^{29}$ Präziser äußern sich Livius und Servius, nach denen der Kultbau sich am Ende des Argiletum befindet: ad infimum Argiletum ${ }^{\circ}$ und circa imum Argiletum. ${ }^{3 \mathrm{I}}$ Nach Ovid stand das Bauwerk am Kreuzpunkt zwischen dem Forum Romanum und dem Caesarforum: „hic ubi iuncta foris templa duobus habes“.32 Der Angabe widerspricht nicht die Überlieferung von Cassius Dio, die den Sakralbau „vor den Toren der Curia“ lokalisiert.33 Die ausführlichste Beschreibung liefert uns Prokop: „Er [Ianus]

\footnotetext{
24 Cass. Dio 56,27,5. Coarelli (I985) I73-I76.

25 Deman (I9I3) 27 lokalisiert das Puteal Libonis mit einem Brunnen, der sich in den Portiken vor der Basilica Aemilia befindet. Diesem Vorschlag folgen Platner u. Ashby (I929) 434, Coarelli (I985) I75f. und Carnabuci (I99I) 3I4. Aufgrund des engen Platzes im Innern der Portiken hätte sich aber dieser Standort als Sitz für das Tribunal nicht geeignet. Im Unterschied dazu bietet der Standort neben dem Sacellum Nr. I an der Via Sacra genügend Platz.

26 Ertel u. Freyberger (2007) II3 Abb. 3; Ertel u. Freyberger (2007) 499 Abb. 6; Freyberger (2009a) 4If. Abb. 25.

27 Sacellum Nr. II. Platner u. Ashby (I929) 278-280; Coarelli (I983) 89-97; Tortorici (I996) 92 f.; zum Gott Ianus: Simon (1990) 618-623.

28 Schon Coarelli (I983) 94 Abb. 30.3I hat das Bauwerk richtig lokalisiert.

29 Sen. apocol. 9 .

30 Liv. I,I9,2.

3I Serv. ad Aen. VIII, 607.

32 Ov. fast. I, 258.

33 Cass. Dio 84,13,3.
} 
hat seinen Tempel auf dem Forum, und zwar vor dem Senatsgebäude, eine kleine Wegstrecke jenseits der Tria Fata“.34 Bei den Tria Fata handelt es sich um die Statuen der drei Fata oder Moiren, die an der Nordseite der Rostra nahe bei der Curia standen.35 Die Nachricht von Prokop beweist zudem, dass dieses Heiligtum wie auch alle anderen Sacella vor der Basilica Aemilia noch in spätantiker Zeit existierten. ${ }^{6}$ Der Bau des Ianus Geminus ist auch in einer Rekonstruktion bei Labacco überliefert. ${ }^{37}$ Nach all diesen Angaben kommt für die Lokalisierung des Tempels nur die Zone zwischen der Südostecke der Curia und der Südwestecke der Basilica Aemilia in Frage und genau in diesem Bereich liegt das Sacellum Nr. Ir.

Auf neronischen Münzen ist das Heiligtum mit seinen großen Türen und Schmuck dargestellt. ${ }^{8}$ Die Beschreibung des Tempels bei Prokop gibt den Zustand des Bauwerks in spätantiker Zeit an: „Der Tempel, ganz aus Bronze hergestellt, hat die Form eines Vierecks und ist so hoch, dass er die Ianusstatue überdeckt. Das eherne Standbild misst fünf Ellen und stellt einen Menschen dar, nur das Haupt trägt zwei Gesichter, von denen das eine zur aufgehenden, das andere zur untergehenden Sonne schaut".39 Es ist eher wahrscheinlich, dass der Kultbau aus einem Mauerwerk bestand, das aber gänzlich mit Bronze verkleidet war..$^{\circ}$ Das Bauwerk wurde mit Sicherheit mehrfach restauriert und dabei auch mit neuer Bronze versehen. Eine umfangreiche Wiederherstellung fand während der Herrschaft des Augustus statt, ${ }^{\mathrm{I}}$ als die Basilica Aemilia bei der Restaurierung Marmorstufen erhielt. Dabei wurden die als Archeia überlieferten Sacella entlang der Via Sacra neu gestaltet und begradigt (Vgl. Abb. I).

Wie alle anderen Archeia, so war auch das Heiligtum des Ianus Geminus ein Grenzheiligtum. Die Via Sacra war die Grenze zwischen den zwei Völkern der Sabiner im Norden und der Römer im Süden, die sich auf dieser Straße eine Schlacht lieferten.4² Die Gründung des Kultes ist eng gebunden an den Friedensvertrag zwischen den Römern und Sabinern: "postquam Romulus et Titus Tatius in foedera convenerunt, Iano simulacrum duplicis frontis effectum est, quasi ad imaginem duorum populorum".43 Dieser Vertrag wurde auf dem Comitium ratifiziert.44 Der Aspekt der Friedenspolitik kommt in dem Heiligtum des Ianus

34 Proc. Goth. I,25.

35 Platner u. Ashby (1929) 539.

36 Nach dem Ziegelmauerwerk zu urteilen, wurde der Kultbau in spätantiker Zeit restauriert: Coarelli (I983) 96.

37 Labacco (I552) Taf. I7.I8; Lanciani (I899) I74f.; Bauer (I996) 37f.; Ertel u. Freyberger (2007) 52If. Abb. 27.

38 Fuchs (I969) 46 Taf. II, I23-I28; Coarelli (I983) 92 Abb. 29.

39 Proc. Goth. I,25.

40 Bronzene Sakralbauten gab es in Rom schon im 4. Jh. v. Chr. oder gar früher: Der Ädil Cn. Flavius ließ im Jahr 304 v. Chr. den bronzenen Schrein der Concordia bei der Graecostasis auf dem Comitium errichten: Platner u. Ashby (1929) I38; Coarelli (1983) 93. Der Sage nach soll Numa die bronzene Ädikula im Quellheiligtum der Camenae gestiftet haben: Platner u. Ashby (1929) 89; Coarelli (1983) 93.

4I Mon. Anc. 2,42-46; Suet. Aug. 22.

42 Macr. Sat. I,9,I7; Serv. ad Aen. VIII, 36I; Varro ling. 5,I65.

43 Serv. ad Aen. XII I98.

44 Plut. Rom. I9,IO; Cass. Dio I, Frg. 5,7. 
Geminus am stärksten zur Geltung, der nach der schriftlichen Überlieferung von Numa Pompilius renoviert wurde. 45

\subsection{Das Heiligtum der Venus Cloacina}

Eng verbunden mit dem Ianus Geminus war auch das Heiligtum der Venus Cloacina, das als Friedensort im Gedächtnis der Völker blieb (Abb. 2). An dieser Stelle schlossen die beiden Könige der ehemals verfeindeten Römer und Sabiner, Romulus und Titus Tatius, einen Waffenstillstand und vollzogen dabei eine rituelle Reinigung an diesem Sacellum. ${ }^{4}$ Kern der Aussage des Mythos ist der Zusammenschluss der an das Forumstal angrenzenden Gemeinwesen. Dieser Synoikismos war eine der wesentlichen Voraussetzungen für die Gründung der Stadt Rom und damit verbunden für die Urbanisierung des Forum Romanum.

Die in ihren Fundamenten erhaltene, nahezu kreisförmige Cella, die auf der Westseite in einer rechteckigen Platte endet, 47 ist auf der Rückseite der im Jahr 42 v. Chr. geprägten Denare des Mussidius Longus dargestellt. $4^{8}$ Auf dem Podium, das mit dem Schriftzug CLOACIN versehen ist, verläuft eine gitterförmige Brüstung. Eine Treppe führt zu dem eingehegten Raum, in dem zwei weibliche Gewandstatuen aufragen. Mit ihrer rechten Hand stützen sie sich auf eine kleine Säule, auf der ein Vogel sitzt. Die rechte der beiden Statuen hält in der linken Hand einen Vogel. Auf der rechteckigen Platte ragte ein turmartiges Gebilde empor, das von Zacken bekrönt ist. In unmittelbarer Nähe des Heiligtums verläuft die Cloaca Maxima, nach der Venus ihren Beinamen Cloacina erhielt, der in diesem Kontext auf Reinigung und weibliche Initiationsrituale verweist.49

Vergleichbar mit dem Heiligtum der Venus Cloacina sind das Heiligtum der Argeer auf dem Esquilin und das allerdings entschieden spätere Pantheon des Agrippa, dessen Temenos kreisförmig war. Wie unlängst A. Grüner zeigen konnte, handelt es sich bei diesen Sacraria um zahlreiche kleine Heiligtümer aus archaischer Zeit, die über das gesamte Stadtareal des republikanischen Rom verteilt und Anlaufstationen bei den Prozessionen waren..$^{\circ}$ Ein entsprechender Sachverhalt ist für die Sacella auf dem Forum Romanum zu postulieren. Die beiden Kultstätten der Venus Cloacina und des Ianus Geminus propagierten zusammen mit dem Tempel der Concordia beim Comitium die Eintracht und den Frieden des römischen Volkes. ${ }^{\text {I }}$

45 Liv. I,I9; Plin. nat. 34, 33; Varro ling 5,165.

46 Fest. 372 L; Dion. Hal. 2,46,3.

47 Coarelli (I983) 83 Abb. 26; Freyberger (2009a) I5 Abb. 4.

48 Fuchs (I969) 3if. Taf. 4,46.47; I6,I52; Coarelli (I983) 84 Abb. 27.

49 Köb (2000) 39.

50 Grüner (2004) 505-512 Abb. 5 .

5I Das Heiligtum des Ianus Geminus steht auch inhaltlich in enger Beziehung mit dem Bogen der Fasti: Dieser Gott war Patron der Fasti und der Magistraten, insbesondere der Konsuln: Coarelli I985, 307. 
All diese kleinen Heiligtümer, die im Bereich des Volcanal und des zentralen Forumsplatzes liegen, haben eine lange Tradition, die sich bis in das 7. oder gar 8. Jh. v. Chr. zurückverfolgen lässt. Sie gewannen durch ihre Verankerung in der Geschichte und ihre Verbindung mit mythologischen Ereignissen und Personen eine enorme Bedeutung. Über Generationen hinweg blieben die Sakralbauten in Erinnerung, worauf die mehrfachen Restaurierungen und Verschönerungen sowie ihre bis in die Spätantike währende Nutzung verweisen.

\section{Der Tempel des Antoninus Pius und der Faustina}

Unweit der Ostseite der Basilica Aemilia befindet sich ein monumentaler Sakralbau, der durch die Weihinschrift auf dem Architrav der Vorhalle als Tempel des Antoninus Pius und der Faustina zu identifizieren ist (Abb. 5)..$^{2}$ Dessen ungewöhnliche Größe und exponierte Lage gegenüber der Regia und vor dem Eingang der Via Sacra in das zentrale Forumsareal werfen die berechtigte Frage auf, ob an dieser prominenten Stelle nicht schon ein Vorgängerbau stand. Indizien für diese Annahme liefern die Bauweise und das Material wie die in der Kirche San Lorenzo in Miranda verbaute Cella aus Peperinquadern (Abb. 6), das Fundament aus Travertinplatten und die Plinthen aus Travertin unter der marmornen Säulenstellung des Pronaos (Abb. 7). Allem Anschein nach gehören all diese Bauelemente zu einem entschieden älteren Bauwerk, das in den Neubau inkorporiert wurde. Erst bei seiner neuen Bestimmung als Kultstätte für das vergöttlichte Kaiserpaar wurde der Sakralbau mit einem neuen Pronaos aus Marmor aufgewertet, wobei auf den Plinthen des älteren Bauwerks nun größere Plinthen aus Marmor der neuen Säulenordnung aufgelegt wurden (Abb. 7). ${ }^{53}$ An der westlichen Längsseite der Cella wurde eine ganze Quaderreihe über dem Podium auf der Schauseite schräg abgearbeitet für ein Auflager, in dem marmorne Platten als Kopfprofil des Podiums eingesetzt wurden (Abb. 8).

Alle Wände des Podiums und der Cella wurden bei der Erneuerung des Tempels in antoninischer Zeit mit Marmorplatten verkleidet, so dass sich das gesamte Bauwerk als ein vollständig neuer Tempel in Marmor präsentierte. Ein Indiz dafür liefert auch die marmorne Bauornamentik, die zweifellos aus antoninischer Zeit stammt (Abb. 9). ${ }^{54}$ Vermutlich wurden im frühen Mittelalter alle Marmorplatten abgenommen. Auf die ehemalige Marmorkleidung verweisen die sekundär angebrachten Löcher zwischen den Tuffblöcken (Abb. IO). In diesen steckten original die Klammern aus Blei, mit denen die Marmorplatten

52 CIL VI Io05: DIVO ANTONINO ET DIVAE FAVSTINAE EX S C. Zum Tempel: Platner u. Ashby (1929) I3f.; Nash I (I96I) 26f. Abb. I5-I7; Cassatella (I993) 4 6f. Abb. 24-28; Köb (2000) IO6-II3 Taf. 5-7; Coarelli (2003) II3; Freyberger (2009a) 24-26 Abb. I4a.b.

53 Freyberger (2009a) 24 Abb. I4a.

54 Pensabene (1996) 239-269. 
Abb. 5 | Rom, Forum Romanum, Tempel des Antoninus Pius und der Faustina, Front, Südseite. Foto H. Behrens, DAI-Rom dig. 2008.2396 .

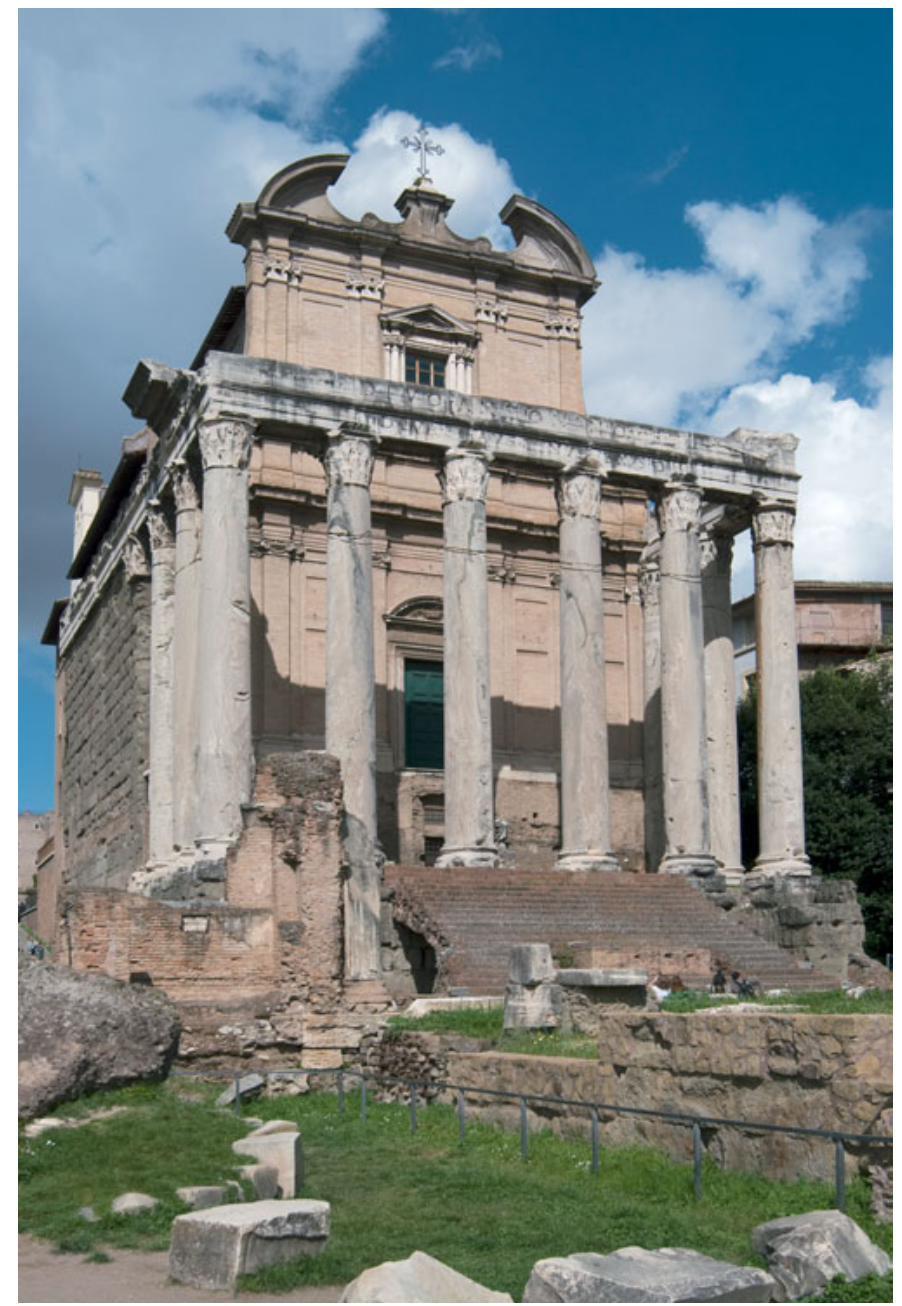

an den Wänden befestigt wurden. Um die Klammern aus dem Mauerwerk herausziehen zu können, mussten die Löcher erst vergrößert werden.

Der ältere Kultbau kann zwar nicht exakt datiert werden, aber die großen Quaderblöcke aus Peperin legen eine Chronologie zwischen der Mitte des 2. und dem frühen I. Jhs. v. Chr. nahe. Ein ähnliches Mauerwerk aus Peperin ist an der Umfassungsmauer des Augustusforums feststellbar (Abb. II). 55 Diese wurde nicht zeitgleich mit dieser Anlage errichtet, wie allgemein angenommen wird, sondern stammt aus einer entschieden älteren Zeit, wahr-

55 Platner u. Ashby (I929) 220-223; Nash I (I96I) 40I-4IO Abb. 490-502; Kockel (I995) 289-295 Abb. II5-I22; Köb (2000) 225-267 Plan 6, I-2; Coarelli (2003) I29-I32; Meneghini (2007) 43-60. 


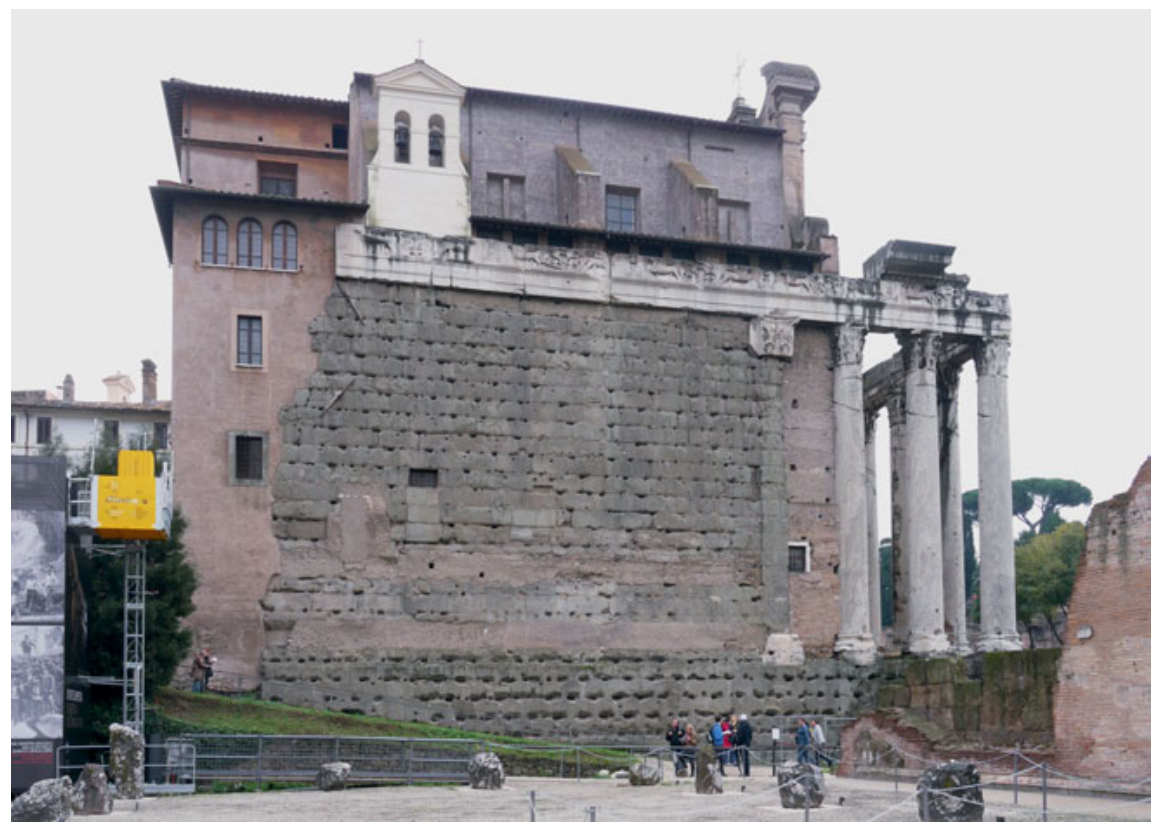

Abb. 6 | Rom, Forum Romanum, Tempel des Antoninus Pius und der Faustina, westliche Längsseite. Foto H. Behrens, DAI-Rom dig. 2010.3383.

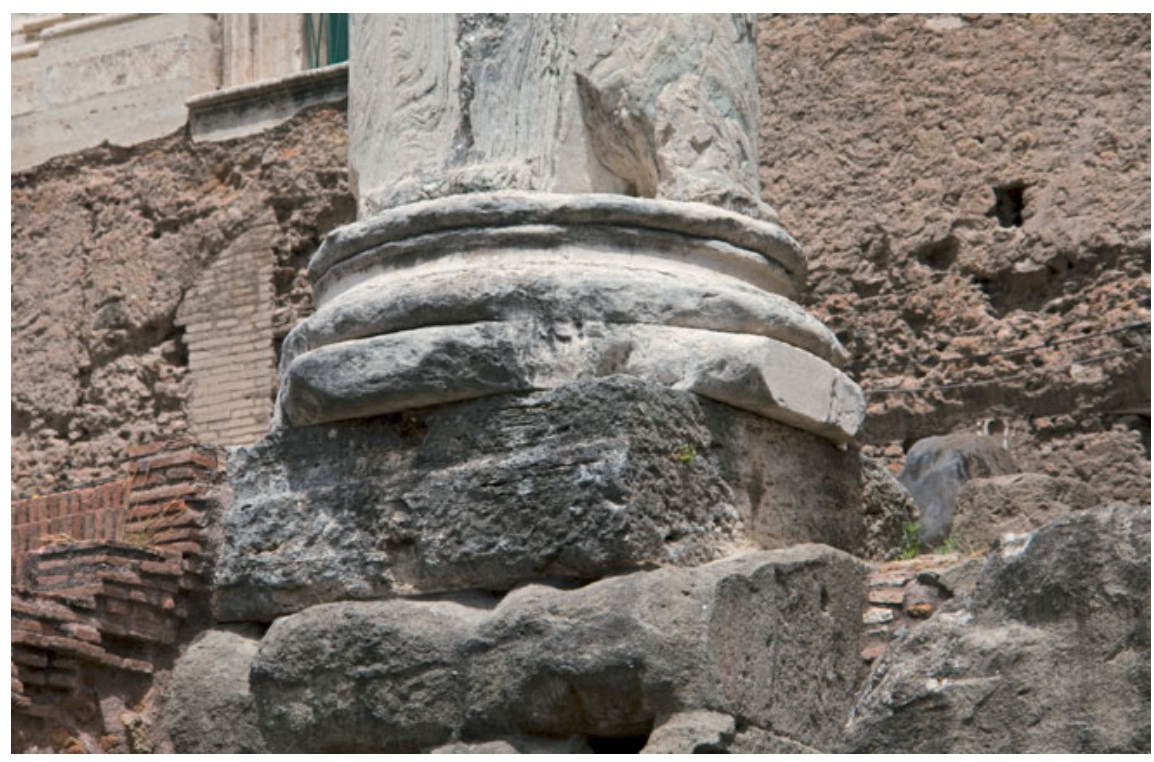

Abb. $7 \mid$ Rom, Forum Romanum, Tempel des Antoninus Pius und der Faustina, Pronaos, Plinthe aus Travertin mit darüber liegenden Plinthe der marmornen Säulenstellung aus antoninischer Zeit. Foto H. Behrens, DAI-Rom dig. 2008.24I6. 

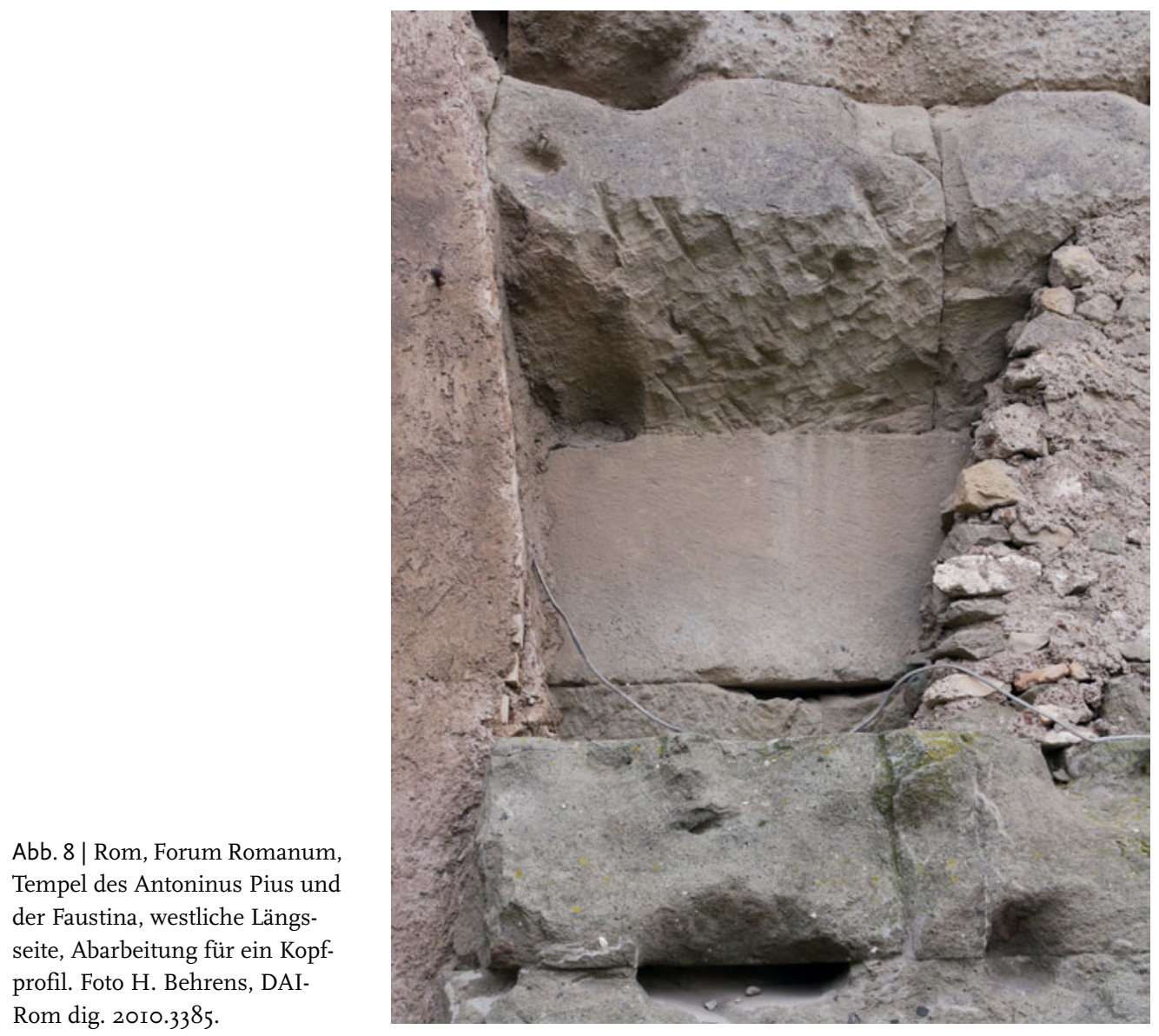

scheinlich aus dem 2. Jh. v. Chr. Vermutlich handelt es sich bei dieser um eine alte Bezirksmauer im Zentrum der Stadt. Ein weiteres Beispiel liefert die nördliche Längsseite des Hadrianeum im Marsfeld, deren Peperinblöcke auf eine spätrepublikanische Entstehungszeit verweisen (Abb. I2)..$^{6}$ Wie bei dem Tempel des Antoninus Pius und der Faustina so wurde auch bei dem Hadrianeum auf dem Marsfeld erst im 2. Jh. n. Chr. sekundär eine marmorne Verkleidung angebracht. Dieser Befund kommt vor allem an den korinthischen Pilasterkapitellen aus Marmor zur Geltung, die erst nachträglich in die abgearbeiteten Blöcke aus Peperin eingesetzt wurden (Abb. 13). Eine derartige aufwendige Arbeit hätte man sich nicht gemacht, wenn das Bauwerk mit der marmornen Verkleidung in nur einer einzigen Phase errichtet worden wäre. Eine ähnliche Mauertechnik kommt auch an der sogenannten La-

56 Platner u. Ashby (I929) 220-223; Nash I (I96I) 457-46I Abb. 558-567; Cipollone (I996) 7f.; Coarelli (2003) $353-355$. 


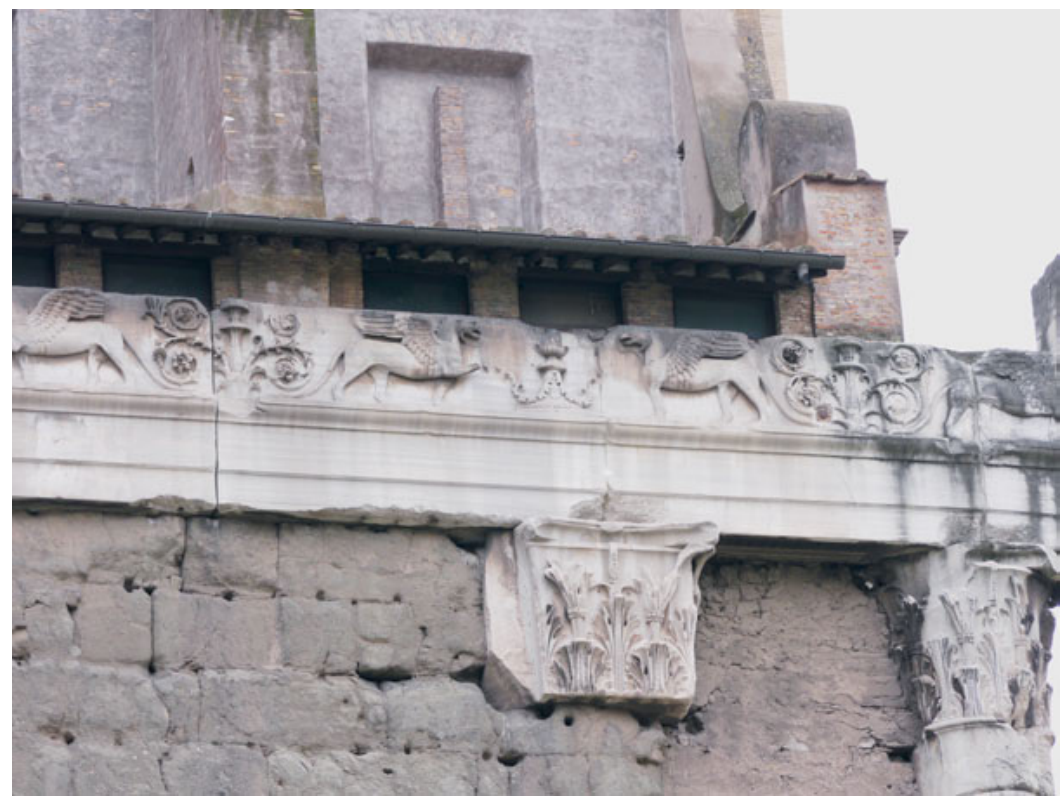

Abb. 9 | Rom, Forum Romanum, Tempel des Antoninus Pius und der Faustina, westliche Längsseite, korinthische Ordnung aus Marmor. Foto H. Behrens, DAI-Rom dig. 20I0.3386.

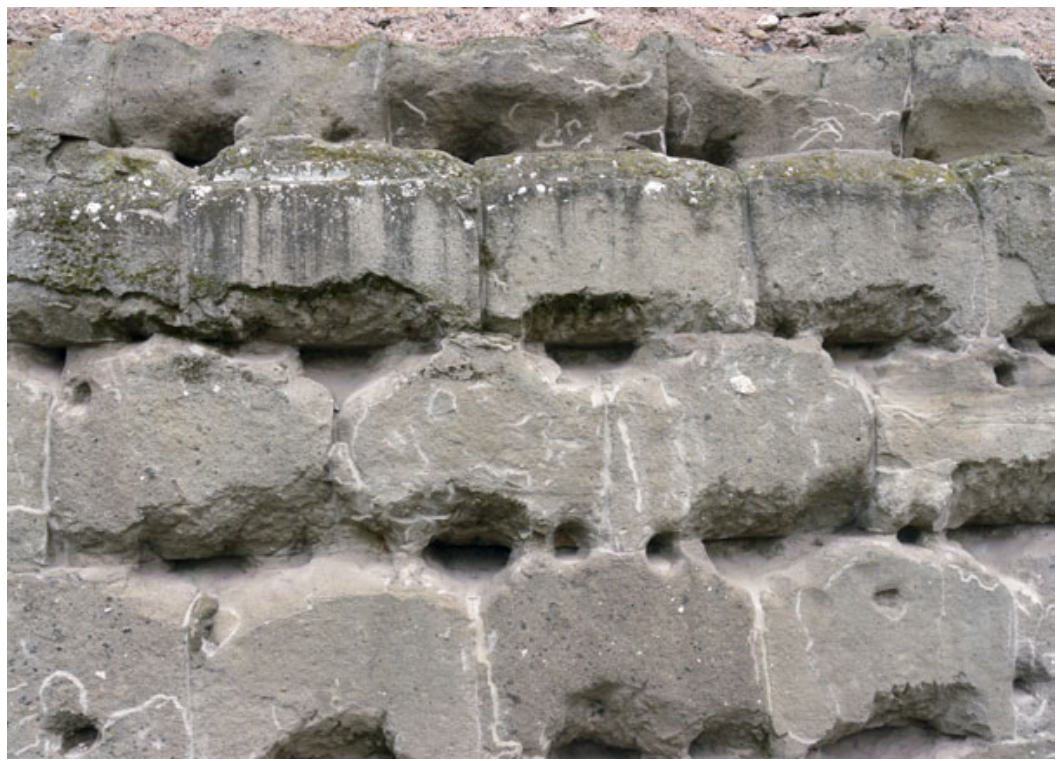

Abb. 10 | Rom, Forum Romanum, Tempel des Antoninus Pius und der Faustina, westliche Längsseite, sekundär angebrachte Löcher zwischen den Quadern aus Tuff. Foto H. Behrens, DAI-Rom dig. 2010.3384. 


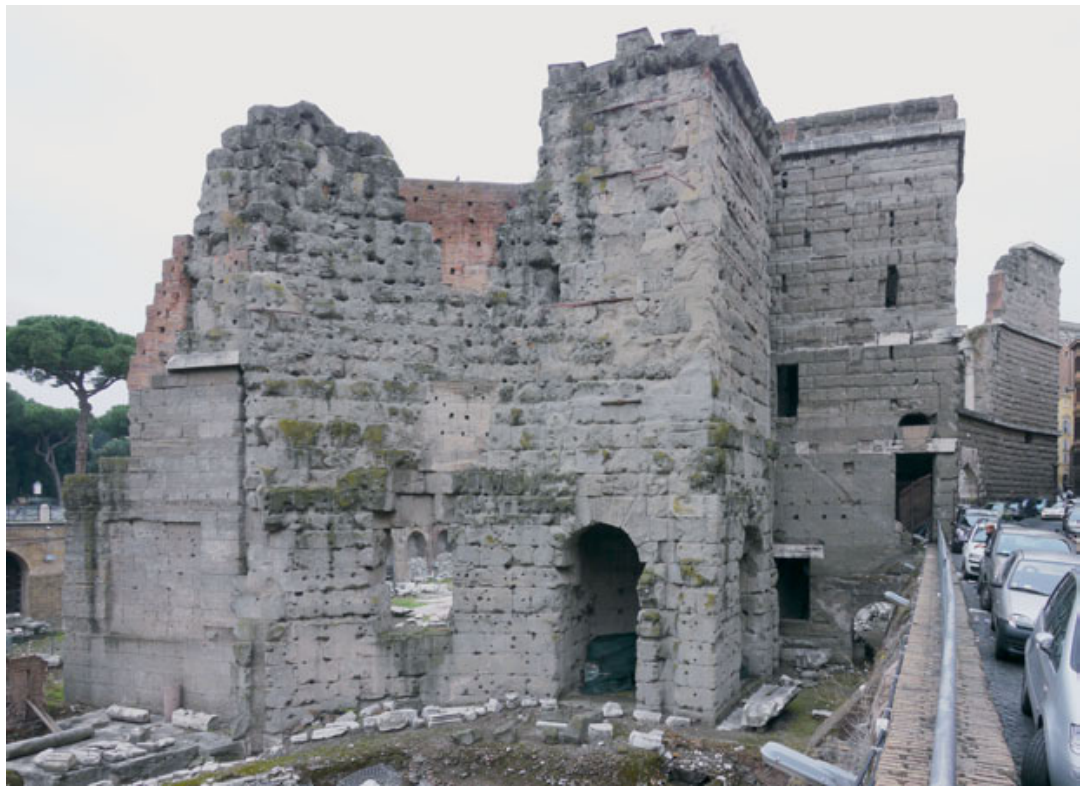

Abb. 11 | Rom, Augustusforum, Umfassungsmauer aus Tuffquadern. Foto H. Behrens, DAIdig. 20I0.338I.

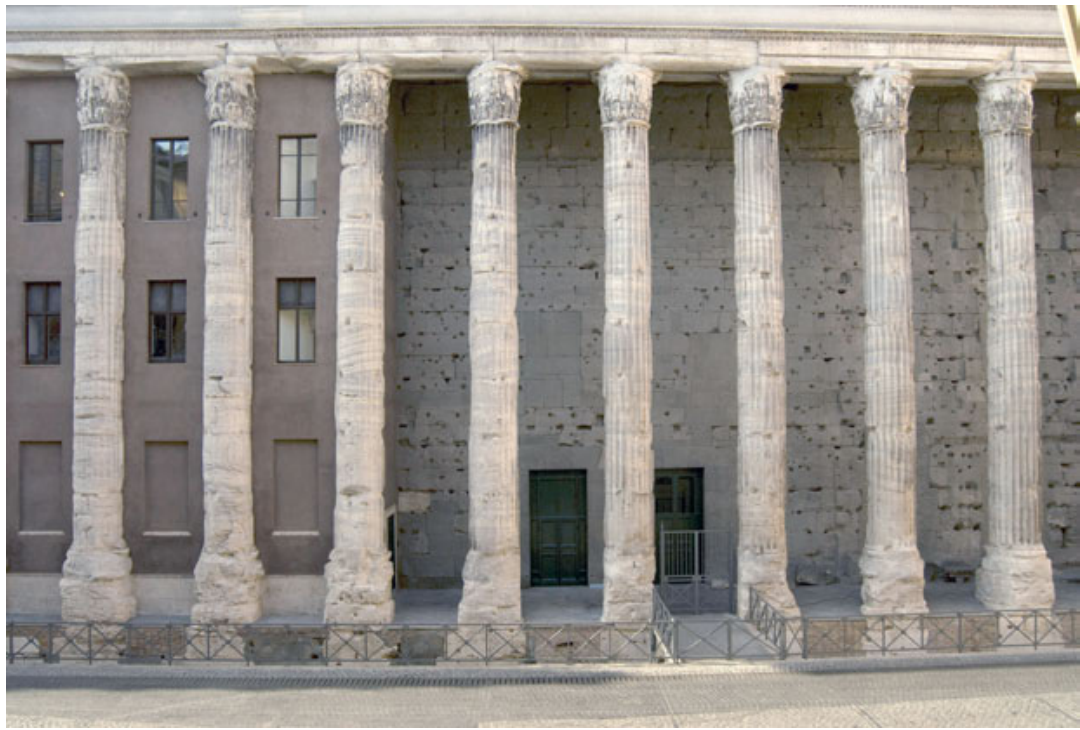

Abb. 12 | Rom, Hadrianeum, nördliche Längsseite. Foto D. Gauss, DAI-Rom dig. 2008.2866 


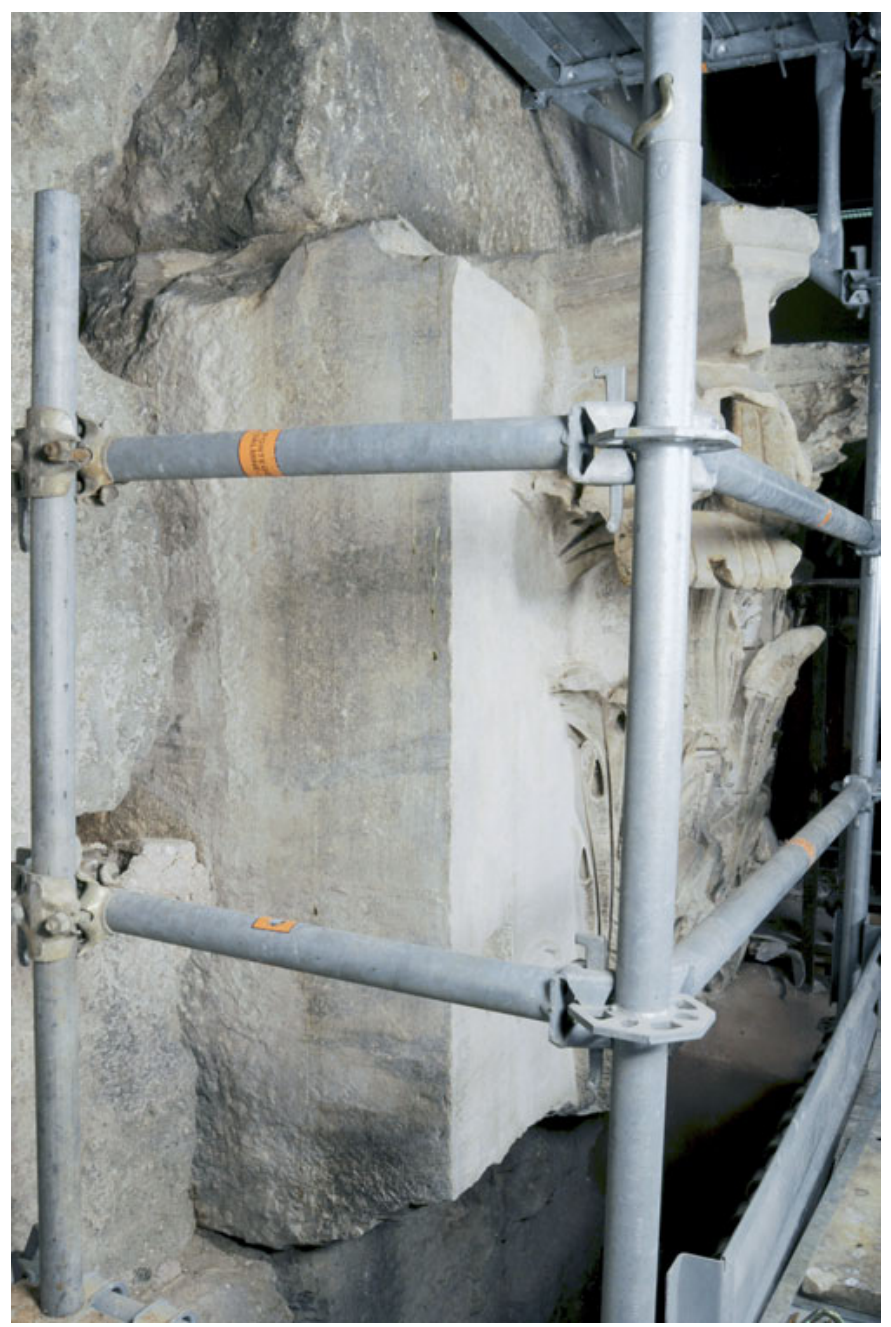

Abb. 13 | Rom, Hadrianeum, nördliche Längsseite, Pilasterkapitell an der Nordwestecke. Foto H. Behrens, DAI-Rom dig. 2008.3318.

germauer in Albano Laziale vor, die wahrscheinlich nicht erst in severischer Zeit für ein Lager errichtet, sondern schon in spätrepublikanischer Zeit als Festungsmauer ausgeführt wurde. 57 Es ist denkbar, dass der Kaiser Septimius Severus im frühen 3. Jh. n. Chr. ein Lager für Detachments der Legio II Parthica innerhalb der Umfassungsmauer errichten ließ. Es wäre nicht verständlich, wenn dieser Regent das gesamte dicht besiedelte Areal aufgelassen und dieses ausschließlich für eine ganze Legion beansprucht hätte.

57 Tortorici (I975) passim; Coarelli (I98I) 85-88. Das Lager wird von A. Busch im Rahmen eines Projekts des Deutschen Archäologischen Instituts Roms untersucht: Busch (20I0) (im Druck); Aglietti u. Busch (20II) (im Druck). 


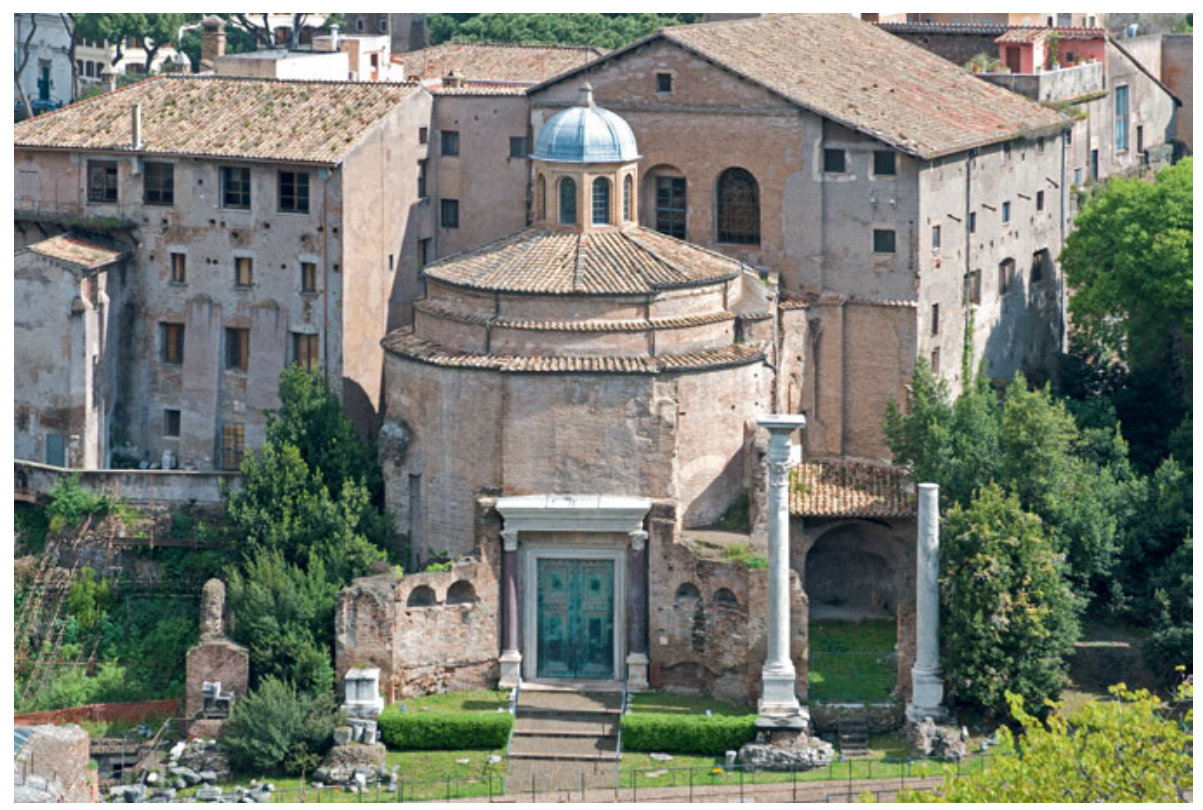

Abb. 14 | Forum Romanum, „Tempel des Romulus“, Front. Foto H. Behrens, DAI-Rom dig. 2008.2407.

Die besondere Lage und die enormen Dimensionen des Tempels auf dem Forum Romanum lassen auf einen bedeutenden Kultbau schließen, dessen ursprüngliche Gottheit bis heute nicht bekannt ist. Die Frage könnte aber mit Hilfe der schriftlichen Überlieferung geklärt werden. Der Katalog der Regionen, eine Beschreibung der I4 Stadtbezirke Roms aus konstantinscher Zeit, zählt in der Region 4 eine Reihe von Bauten auf, unter anderem den Tempel der Faustina und den Tempel des Iuppiter Stator..$^{8}$ In dieser Region liegen das Templum Pacis und die Bauwerke auf dem Forum nördlich der Via Sacra. Ist die Position des erstgenannten Tempels bekannt, so bleibt zu fragen, an welcher Stelle der Bau des Iuppiter Stator im nördlichen Forumsbereich stand. Nach Ausweis einer Inschrift vom Forum, deren genauer Fundort nicht bekannt ist, huldigten die Liktoren dem Gott mit einem speziellen Kult.59 Eine weitere Weihinschrift der Liktoren wurde in unmittelbarer Nachbarschaft des „Tempels des Romulus“ gefunden (Abb. I4), der sich unweit des Tempels des Antoninus Pius und der Faustina befindet. ${ }^{60}$ Der Kult dieser Staatsdiener war wie der Kult der Calatores eng mit dem Rex Sacrorum und dem Pontifex Maximus verbunden.

Damit ergibt sich eine enge topographische und funktionale Verbindung des Tempels des Iuppiter Stator mit der Regia, der Domus Regis, und dem Tempel der Vesta. Der Zu-

58 Das Curiosum bezeichnet den Bau als „aedem Iobis“, die Notitia als „aedem Iovis Statoris“: Coarelli (I983) 28.

59 CIL VI 435.

60 CIL VI 3I295 a. 
sammenhang dieser Gebäude, deren Tradition bis zum Beginn der Königszeit zurückreicht, wird durch eine Beschreibung des Forum Romanum bei Ovid in den Tristia bestätigt. ${ }^{6 I}$ Dabei zählt der antike Poet die Via Sacra, den Vestatempel, die Regia, die Porta Mugonia und den Tempel des Iuppiter Stator auf. ${ }^{62}$ Die gleichen Bauwerke überliefert Tacitus in umgekehrter Reihenfolge, der den Tempel des Iuppiter Stator, Numas Königsburg und das Heiligtum der Vesta in einem Zug nennt. ${ }^{63}$ In Übereinstimmung mit dieser Überlieferung stehen auch die Angaben der antiken Autoren Livius ${ }^{64}$ und Plinius ${ }^{65}$, die beide den Tempel des Iuppiter Stator gegenüber der Domus Regis lokalisieren. Nach den vier übereinstimmenden topographischen Beschreibungen kann der Tempel dieses Gottes nur der Stelle auf dem Forum Romanum zugeschrieben werden, an der heute der Sakralbau des Antoninus Pius und der Faustina steht. ${ }^{66}$ Diesem Ergebnis widerspricht auch nicht der archäologische Befund, aus dem sich zwei Bauphasen des Gebäudes ableiten lassen. Nach ihrer Divinisierung wurden Faustina und Antoninus Pius als neue Gottheiten in den Tempel aufgenommen, wobei aber der von Romulus gegründete Kult des Iuppiter Stator fortgesetzt wurde. Vermutlich erhielt neben diesem Gott auch dessen Paredra, Iuno Regina, kultische Verehrung. Der Kult des neu hinzugekommenen Götterpaars stand nun in unmittelbarer Beziehung zur Gründungsgeschichte Roms. Diesem Vorgang lag die Absicht zugrunde, an die alte Tradition anzuknüpfen. Ein entsprechender Sachverhalt gilt wohl auch für den Tempel des Divus Vespasianus am Osthang des Kapitols ${ }^{67}$ und für das Hadrianeum (Abb. I2.I3) ${ }^{68}$ Beide Tempel, in denen divinisierte Kaiser verehrt wurden, hatten Vorgängerbauten aus spätrepublikanischer Zeit.

Der Tempel des Iuppiter Stator, die Regia und das Heiligtum der Vesta liegen auf der zentralen Nord-Süd-Achse des Forum Romanum und bilden damit eine räumliche und kultische Einheit, die für das religiöse Leben der Stadt von höchster Bedeutung war.

6I Ov. trist. 3,I.

62 Bei der Aufzählung handelt es sich um das Motiv des poetischen Stadtrundgangs, das in augusteischer Zeit ein beliebtes Thema war: Amann (2006) I34.

63 Tac. ann. 15,4I.

64 Liv. I,4I,4.

65 Plin. nat. 34,29.

66 Coarelli (I983) 33 Abb. 6 lokalisiert den Tempel des Iuppiter Stator weiter östlich unweit der Carinae. Diese Annahme ist nicht haltbar, zumal in diesem Bereich das Templum Urbis Romae stand und damit kein Platz für den monumentalen Tempel zur Verfügung stand.

67 Platner u. Ashby (I929) 556; Nash II (I962) 50I-504 Abb. I320-I323; De Angeli (I999) I24f. Abb. 69-7I; Köb (2000) IOI-I06; Coarelli (2003) $78 \mathrm{f}$.

68 s.o. Anm. 56 . 


\section{Der „Tempel des Romulus“}

Östllich des Tempels des Iuppiter Stator lag ein weiterer ranghoher Kultbau. Das Bauwerk ragt hinter dem „Tempel des Romulus“ an der Stelle empor, ${ }^{69}$ die heute die Kirche SS. Cosma e Damiano einnimmt (Abb. I4). Bis heute gilt das Gebäude als die Bibliotheken des Templum Pacis (Abb. I5), an dessen Rückseite der bekannte marmorne Stadtplan der Forma Urbis angebracht war (Abb. I6)..$^{\circ}$ Von dem Bauwerk sind zwei von Norden nach Süden parallel verlaufende Mauern aus Aniene-Tuff in Höhe von I7 $m$ erhalten, die sich in der Form und dem Material von der Ziegelmauer des Templum Pacis diametral unterscheiden. Quader aus Aniene-Tuff sind in annähernd gleich hohen Lagen aufeinandergeschichtet, wobei die Blöcke unterschiedlich lang und nicht im Wechsel von Bindern und Läufern angeordnet sind.7 Auf der Ostseite befindet sich ein Eingang, dessen Leibungen aus Travertinquadern bestehen, der Türbogen weist Keilsteine aus Travertin auf (Abb. I7). ${ }^{72}$ Ein weiteres aus Travertin bestehendes Portal auf der Westseite ist von einem bogenförmigen Fenster bekrönt, das sekundär mit Tuffsteinen verschlossen wurde (Abb. I8). ${ }^{73}$ Darüber verläuft eine Mauer aus Peperin.74 Diese altertümliche Bauweise steht in scharfem Kontrast zu den Wänden des Templum Pacis, die samt und sonders aus Ziegelmauern bestehen.75 Nach der Bauweise und dem Material zu urteilen, insbesondere dem Tuff, sind die Längsseiten spätrepublikanisch, vermutlich in das späte 2. oder frühe I. Jh. v. Chr., zu datieren und gehören damit einem entschieden älteren Bauwerk an als dem Templum Pacis. ${ }^{76}$

Für die Deutung und Lokalisierung des Bauwerks ist der während der Amtszeit des Papstes Felix IV. (526-530) entstandene Liber Pontificalis von entscheidender Aussagekraft. Den Angaben zufolge ließ dieser Papst die Basilika der Heiligen Cosmas und Damianus in Rom an dem Ort errichten, der Via Sacra genannt wird, neben dem Tempel der Stadt Rom.77 Aus dem Bericht des spätantiken Historiographen Aurelius Victor geht hervor, dass der Kaiser Maxentius eine Basilica und das Urbis fanum errichten ließ.78 Diesen Sachverhalt bestätigt ein Passus im Chronographen von 354.79 Zunächst stehen diese Angaben in einem scheinbaren Widerspruch zu der spätrepublikanischen Datierung nach dem architektonischen Befund. Vergegenwärtigt man sich aber, dass der „Tempel des Romulus“

69 Zum „Tempel des Romulus“: Whitehead (1927) I-I8 Plan I.2; Platner u. Ashby (1929) 450; Nash II (I962) 268-27I Abb. I023.I026; Papi (I999) 2I0-2I2 Abb. 85-90; Coarelli (2003) IO8-III.

70 Carettoni u.a. (I960) I90 mit Abb.; Nash I (I96I) 439 Abb. 536.

7I Nash I (I96I) 440f. Abb. 537.538.

72 Castagnoli u. Cozza (1956-58) I22.I3I-I34 Abb. 3.I7.I9 Taf. 4.

73 Castagnoli u. Cozza (I956-58) I23-I30 Abb. 6 Taf. 2.3.

74 Nash I (1961) 442 Abb. 539.

75 Carettoni u.a. (1960) Taf. I Abb. 26.27.

76 Bis heute werden diese Mauern dem Templum Pacis zugeschrieben und damit in die flavische Zeit datiert.

77 Liber Pontificalis, ed. Duchesne I 279: hic fecit basilicam sanctorum Cosmae et Damiani in urbe Roma, in loco qui appellatur via sacra, iuxta templum urbis Romae. Whitehead (1927) If.

78 Aur. Vict. Caes. 40, 26: ... cuncta opera quae magnifice construxerat [sc. Maxentius] urbis fanum atque basilicam.

79 Chronogr. a. 354, p. I48,32: [Maxentius:] ... Hoc imperatore templum Romae arsit et fabricatum est. 


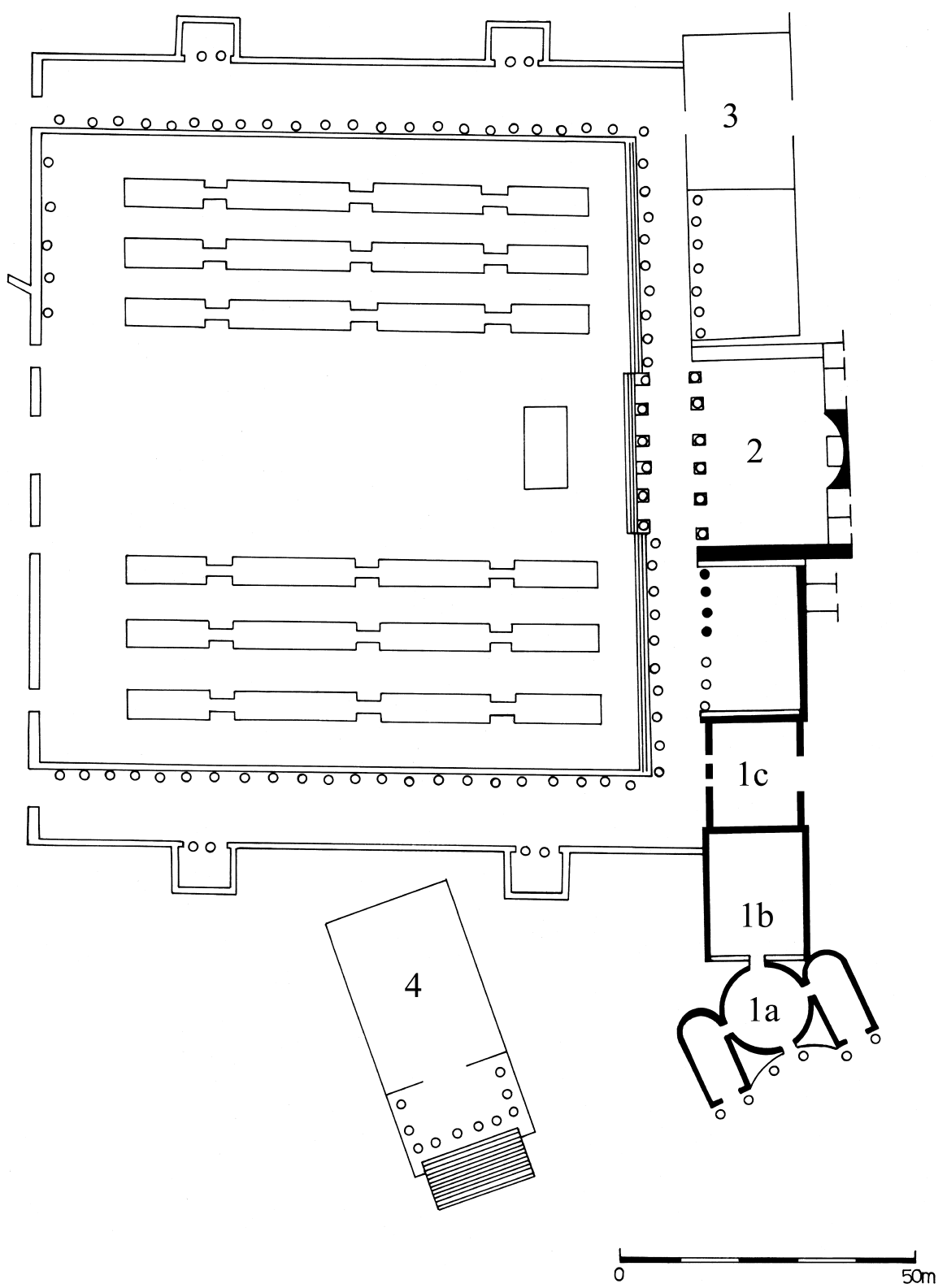

Abb. ${ }_{15} \mid$ Rom, Templum Pacis, schematischer Grundriss. Ia-c: Templum Urbis Romae („Bibliotheken“); a: Vorhalle („Tempel des Romulus“), b: Cella, c: Tempelarchiv; 2: Tempel der Pax; 3: Tempel der Penaten (?); 4: Tempel des Antoninus Pius und der Faustina mit Vorgängerbau des Iuppiter Stator (?). Benennungsvorschlag der Bauten: K. S. Freyberger unter Verwendung eines Plans nach Nash I I96I, 439 Abb. 536; Umzeichnung J. Telemann. 


\begin{abstract}
Abb. 16| Rom, Templum Urbis Romae, Rückwand mit antiken Dübel- und modernen Balkenlöchern. Foto H. Behrens, DAIRom dig. 2010.3538.
\end{abstract}

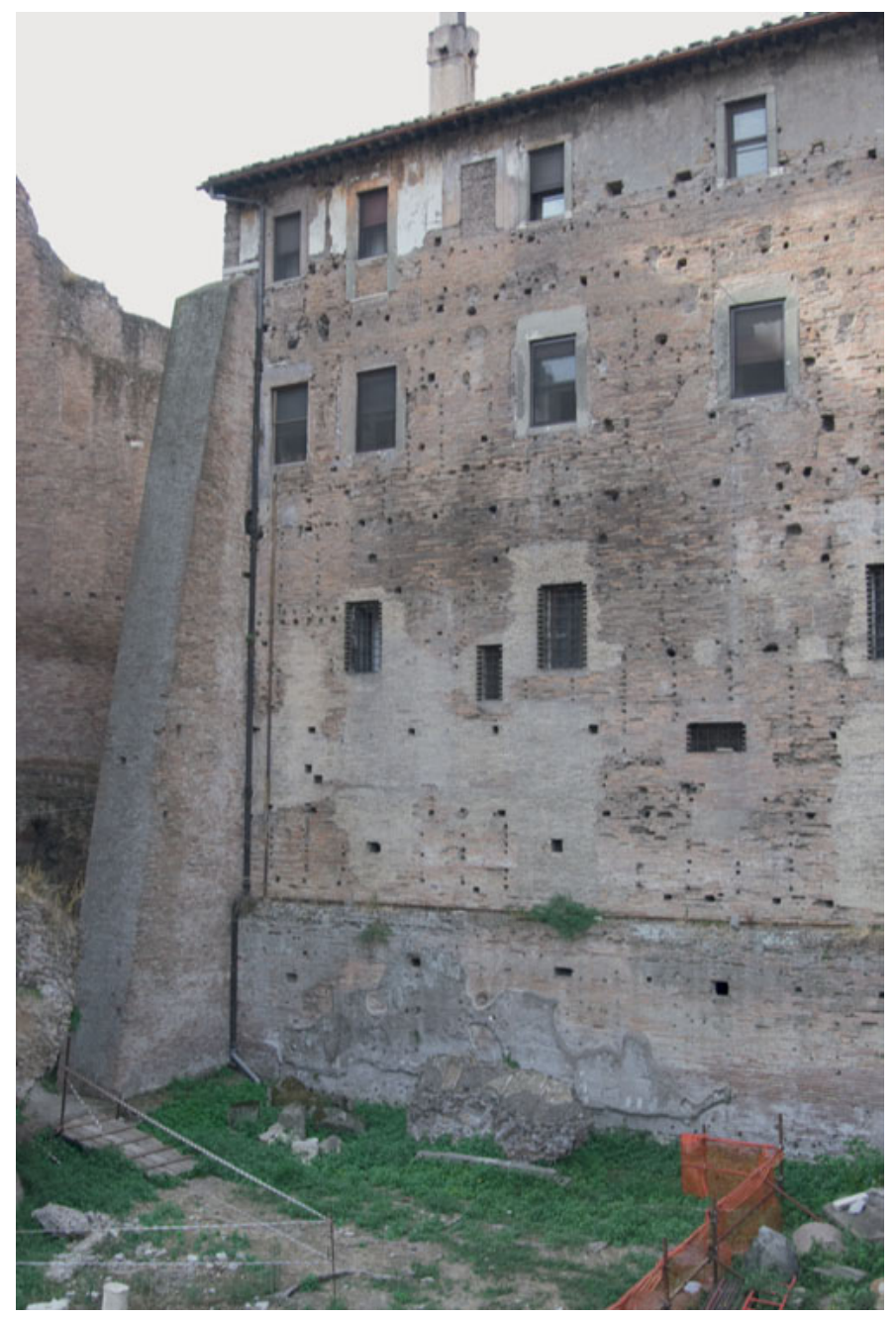

nichts anderes war als die Eingangshalle des Urbis fanum, so löst sich der Widerspruch auf (Abb. 14). ${ }^{80}$ Es war der Kaiser Maxentius, der nach Ausweis der Ziegelstempel den Rundbau neu errichten und diesen an der Front zur Via Sacra mit einer prächtigen Spolienfassade ausstatten ließ. Vermutlich hatte ein Brand den Vorgängerbau des Pronaos so stark beschädigt, dass er vollständig erneuert werden musste. Wahrscheinlich hatte schon der äl-

80 Zur Deutung des „Tempels des Romulus“ als Eingangshalle des Urbis fanum: Freyberger (2009a) II2 Abb. 76; II4-II7. Schon Lanciani (I897) 2I3-2I7 deutete die Anlage zu Recht als das templum sacrae urbis. Whitehead (I9I3) I43-I65 folgte zunächst der Ansicht von Lanciani, die er aber später verwarf, wobei er die Tuffmauer in die augusteische Zeit datierte und sie für die Temenosmauer des Tempels der Penaten hielt: Biasiotti u. Whitehead (I924/25) 83-95; Whitehead (I927) I-I8. 


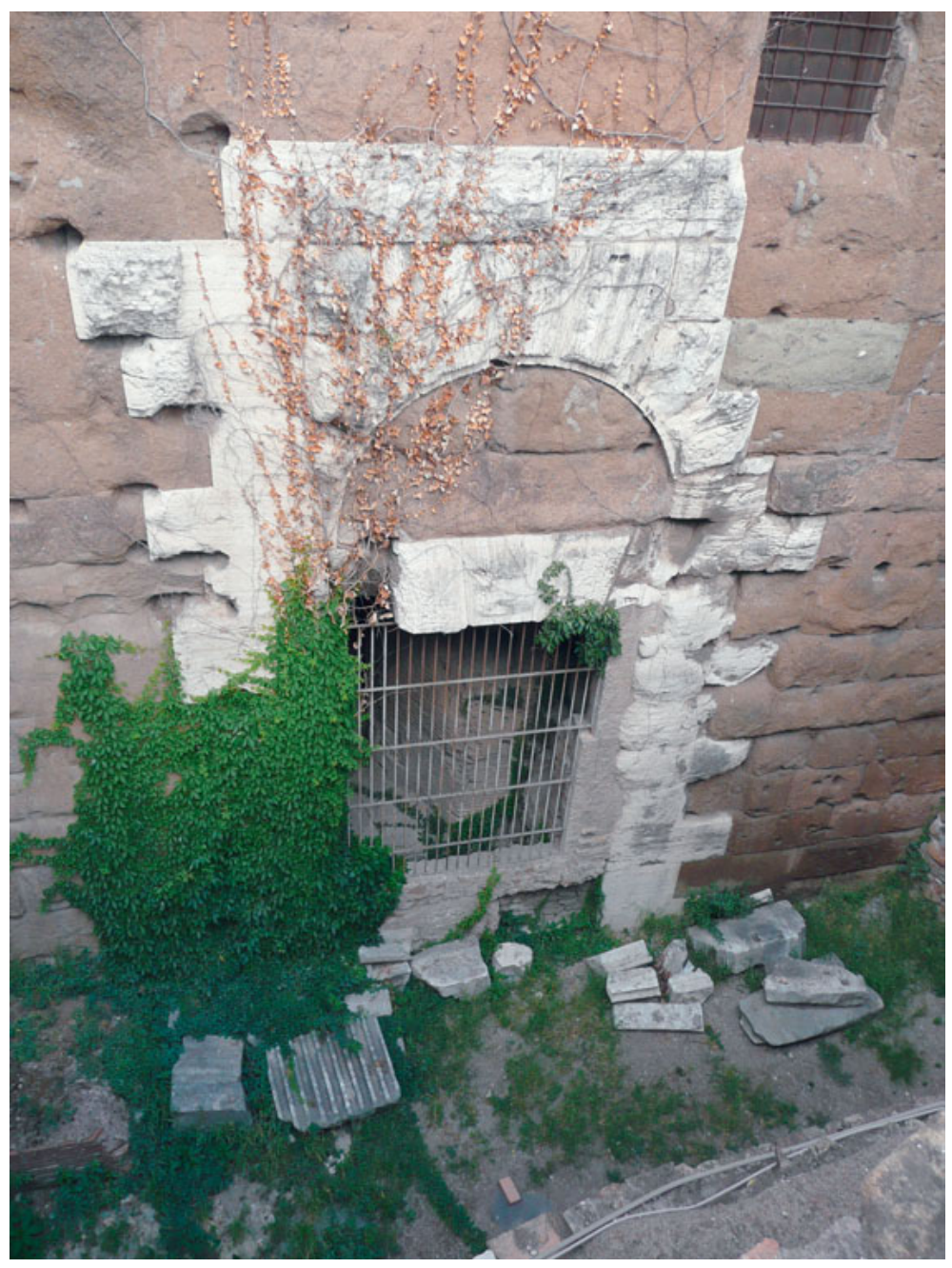

Abb. $17 \mid$ Rom, Kirche SS. Cosma e Damiano, Ostwand mit antikem Eingang. Foto H. Behrens, DAI-Rom dig. 20I0.3545. 


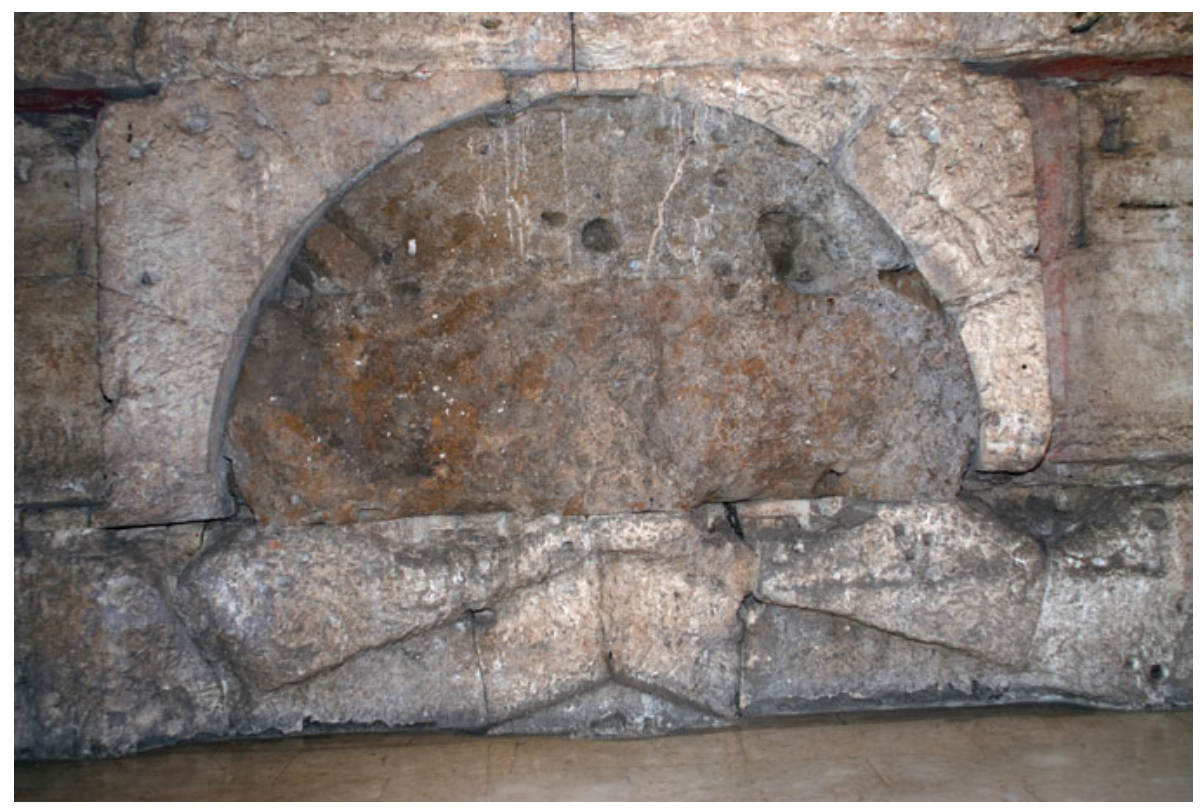

Abb. 18 | Rom, Kirche SS. Cosma e Damiano, Westwand mit sekundär zugesetztem Fenster. Foto H. Behrens, DAI-Rom dig. 20I0.354I.

tere Bau die Form eines Zylinders, der als Scharnier zwischen der orthogonal zur Via Sacra ausgerichteten Eingangsfront und der dazu schräg positionierten Cella fungiert. ${ }^{8 \mathrm{r}}$ Hinter dem Pronaos lag die Cella des templum urbis Romae, in dem sich heute die Kirche auf einem entschieden höheren Niveau befindet. Die großen Eingänge an den Längsseiten schließen eine Zugehörigkeit dieses Traktes zur Cella aus. Auf dem Grundriss des Bauwerks, den Paul Whitehead I927 publizierte, verjüngt sich der rückwärtige Teil des Gebäudes (Abb. I9). ${ }^{82}$ Mit großer Wahrscheinlichkeit war dieser Trakt das Tempelarchiv mit dem nahe gelegenen Sitz der Stadtpraefektur, an dessen Rückseite einst die berühmte Forma urbis Romae angebracht war (Abb. I6). Kein Bau in Rom eignete sich besser als Träger für den marmornen Stadtplan als das templum urbis Romae.

Dem nahe an der Südostecke des Templum Pacis gelegenen Urbis fanum stand wohl an der Nordostecke ein Sakralbau gegenüber, der einen ähnlichen Stellenwert gehabt haben musste wie der Stadttempel. Wahrscheinlich stand an diesem Ort der Tempel der Penaten, der nach den Angaben von Dionysius über einen kleinen, zu den Carinae führenden Weg

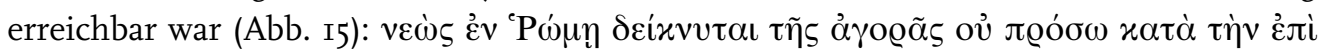

8I Die schräge Ausrichtung des Tempels zur Via Sacra ist ein weiteres Indiz für das hohe Alter des Sakralbaus. Unter den Tabernen der Basilica Aemilia sind Mauerzüge erkennbar, die schräg zur Via Sacra verlaufen. Erst die um 200 v. Chr. errichteten Tabernen sind orthogonal zu dieser ausgerichtet.

82 Whitehead (I927) Plan I.2. 


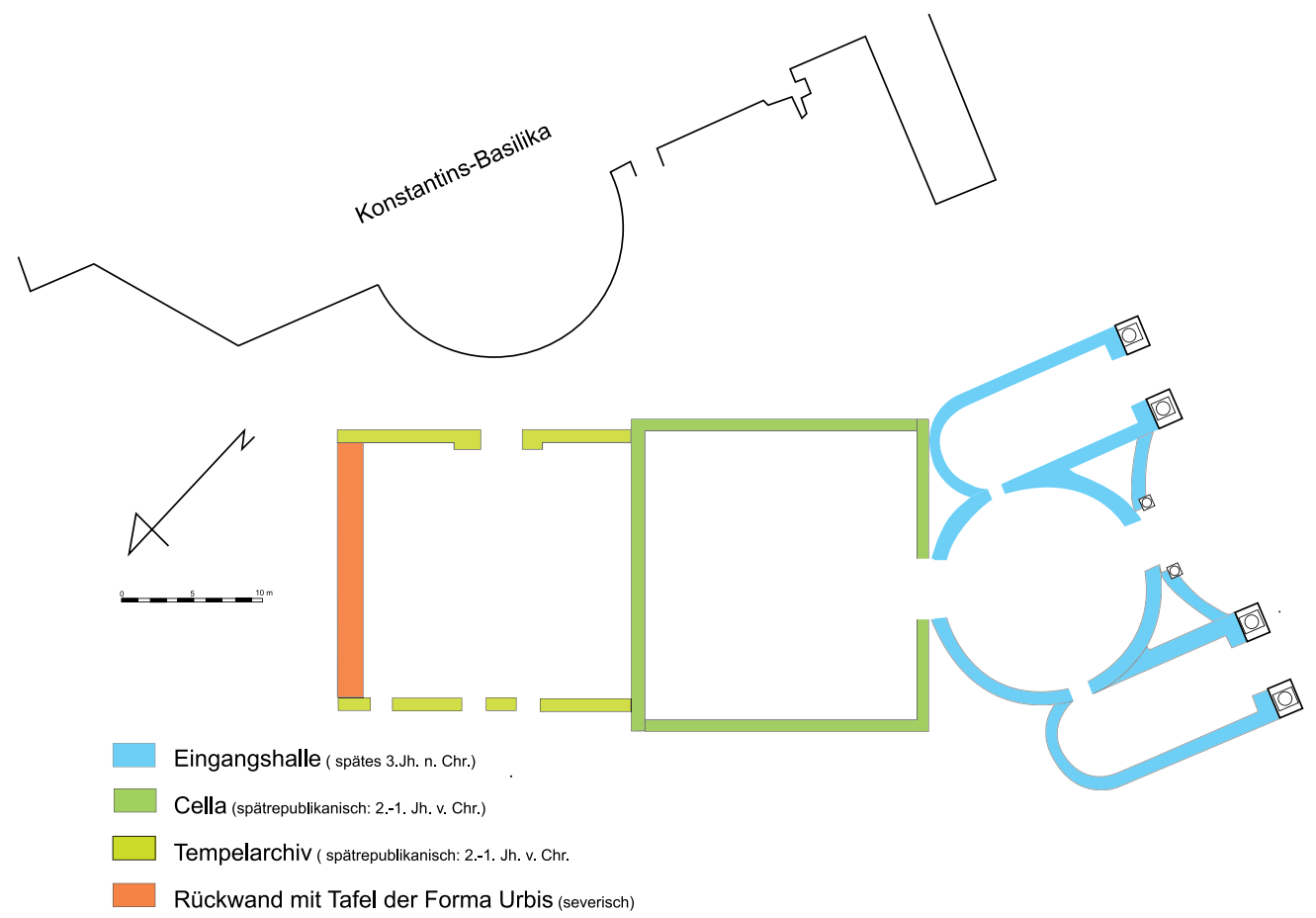

Abb. 19|Rom, Templum Urbis Romae, schematischer Grundriss, hypothetische Rekonstruktionsskizze. Entwurf: K. S. Freyberger; digitale Zeichnung und Bearbeitung: M. Schützenberger. Digitale Bildbearbeitung: H. Behrens - D. Gauss.

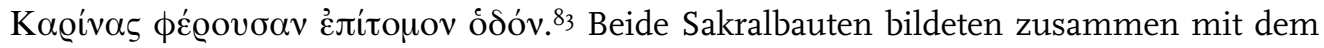
späteren Tempel der Pax eine Kultachse. Erweist sich diese Lokalisierung als korrekt, dann wären bei dem Bau des Templum Pacis in flavischer Zeit die traditionellen Kultbauten in die neue Anlage miteinbezogen und augenfällig in Verbindung mit dem Tempel der Pax gesetzt worden.

Es ist wohl kein Zufall, dass dieses Heiligtum sich ganz in der Nähe des Tempels des Iuppiter Stator befand. Allem Anschein nach waren diese Sakralbauten eng mit der Genese von Rom verknüpft und hatten damit verbunden einen überragenden Stellenwert. Sie erinnerten an die Ahnen Roms, an Romulus, Aeneas und Numa Pompilius, deren Tempel den heiligen Charakter der Stadt, der Urbs Sacra, wirkungsvoll in Erscheinung setzten. Die Bedeutung dieser Heiligtümer kommt auch in deren langen Tradition zur Geltung. Waren die Gründungsbauten noch von kleiner Gestalt, so wurden sie im 2. und I. Jh. v. Chr. monumental ausgebaut und in der Kaiserzeit luxuriös mit Marmor ausgestattet.

83 Dion. Hal. I,68, r. Zum Tempel der Penaten: Palombi (I997) 435-463; Palombi (I999) 75-78. 


\section{Literaturverzeichnis}

\section{Amann (2006)}

M. Amann, Komik in den Tristien Ovids, Basel.

Balbi de Caro (1989)

S. Balbi De Caro, La banca a Roma. Vita e costumi dei Romani antichi 8, Rom.

\section{Bauer (1996)}

F. A. Bauer, Stadt, Platz und Denkmal in der Spätantike, Mainz.

Biasiotti u. Whitehead (1924/25)

G. Biasiotti - Philip B. Whitehead, „La chiesa dei SS. Cosma e Damiano al Foro Romano e gli edifici preesistenti“ Rend PontAc 3, I924/25, 83-I22.

Busch (2010)

A. W. Busch, Von der Kaiservilla zu den castra. Das Lager der legio II Parthica in Albano Laziale und seine Vorgängerbebauung, Kölner und Bonner Archaeologica 1, (im Druck).

\section{Aglietti u. Busch (20II)}

S. Aglietti u. A. W. Busch, „Dalla villa imperiale ai Castra Albana: le nuove ricerche del DAI sull'accampamento della legione II Parthica e sui suoi dintorni“, in: G. Ghini (Hg.), Lazio e Sabina 7, (im Druck).

Carettoni u.a. (1960)

G. Carettoni, A. M. Colini, L. Cozza u. G. Gatti, La pianta marmorea di Roma antica, Roma.

\section{Carnabuci (I99I)}

E. Carnabuci, „L'angolo sud-orientale del Foro Romano nel manoscritto inedito di Giacomo Boni“, MemLinc 9/I, 247-365.

\section{Cassatella (1993)}

A. Cassatella, „Antoninus, Divus et Faustina, Diva, Aedes, Templum“, in: Steinby, E. M (Hg.), Lexicon Topographicum Urbis Romae I, Rom, $46 \mathrm{f}$.

Castagnoli u. Cozza (1956-58)

F. Castagnoli u. L. Cozza, „L'angolo meridionale del Foro della Pace“, BCom 76, II9-I42.

\section{Chioffi (1995)}

L. Chioffi, „Fornix Fabianus“, in: Steinby, E. M. (Hg.), Lexicon Topographicum Urbis Romae II, Rom, 264-266.

\section{Chioffi (1996)}

L. Chioffi, Gli Elogia Augustei del Foro Romano, Rom.

\section{Chioffi (1999)}

L. Chioffi, „Puteal Libonis / Scribionianum“, in: Steinby, E. M. (Hg.), Lexicon Topographicum Urbis Romae IV, Rom, I7I-I73. 


\section{Cipollone (1996)}

M. Cipollone, „Hadrianus, Divus, Templum; Hadrianeum“, in: Steinby, E. M. (Hg.), Lexicon Topographicum Urbis Romae III, Rom, $7 \mathrm{f}$.

\section{Coarelli (I98I)}

F. Coarelli, Dintorni di Roma, Roma - Bari.

Coarelli (1983)

F. Coarelli, Il Foro Romano I. Periodo Archaico, Rom.

\section{Coarelli (1985)}

F. Coarelli, Il Foro Romano II. Periodo Repubblicano e Augusteo, Rom.

\section{Coarelli (1993)}

F. Coarelli, „Cloacina, Sacrum“, in: Steinby, E.M. (Hg.), Lexicon Topographicum Urbis Romae I, Rom, 29of.

Coarelli (2003)3: F. Coarelli, Roma, Roma - Bari.

\section{De Angeli (1999)}

S. De Angeli, „Vespasianus, Divus, Templum“, in: Steinby, E. M. (Hg.), Lexicon Topographicum Urbis Romae V, Rom, I24f.

\section{Deman (1913)}

E. B. van Deman, „The Porticus of Gaius and Lucius“, AJA I7, I4-28.

\section{Ertel u. Freyberger (2007)}

C. Ertel u. K. S. Freyberger, „Nuove indagine sulla Basilica Aemilia nel Foro Romano: storia architettonica, funzione e significato“, Archeologia Classica 58, I09-I42.

\section{Freyberger, Ertel, Lipps, Bitterer (2007)}

K. S. Freyberger, C. Ertel, J. Lipps u. T. Bitterer, „Neue Forschungen zur Basilica Aemilia auf dem Forum Romanum“, $R M$ II3, 493-552.

\section{Freyberger (2009a)}

K. S. Freyberger, Das Forum Romanum, Mainz.

\section{Freyberger (2009b)}

K. S. Freyberger, „Le basiliche“, in: H. v. Hesberg u. P. Zanker (a cura di) Storia dell'architettura italiana. Monumenti di Roma, Milano, I64-I7I.

\section{Freyberger (2010)}

K. S. Freyberger, „La basilica Emilia. Un edificio di lusso al centro dell'Urbs. - The Basilica Aemilia. A Luxurious Building in the Center of the Urbs“, in: Maria Antonietta Tomei (a cura di), memorie di roma-memories of rome, Milano, I6-57.

\section{Fuchs (1969)}

G. Fuchs, Architekturdarstellungen aufrömischen Münzen der Republik und der frühen Kaiserzeit, Berlin. 


\section{Gaggiotti (1985)}

M. Gaggiotti, „Atrium Regium - Basilica (Aemilia): una insospettata continuità storica e una chiave ideologica per la soluzione del problema dell'origine della basilica“, AnalRom I4, I985, 53-80.

\section{Grüner (2004)}

A. Grüner, „Das Pantheon und seine Vorbilder“, RM III, 495-5I2.

\section{Kockel (1995)}

V. Kockel „Forum Augustum“, in: Steinby, E. M. (Hg.), Lexicon Topographicum Urbis Romae II, Rom, 289-295.

Köb (2000)

I. Köb, Rom - ein Stadtzentrum im Wandel. Untersuchungen zur Funktion und Nutzung des Forum Romanum und der Kaiserfora in der Kaiserzeit, Hamburg.

Labacco (1557)

A. Labacco, L'architettura nel qual si figurano alcune notabili antiquità di Roma, Roma.

\section{Lanciani (I897)}

R. Lanciani, Ruins and Excavations of Ancient Rome, London.

\section{Lanciani (I899)}

R. Lanciani, „Le escavazioni del Foro“, BCom 27, 169-204.

\section{Meneghini (2007)}

R. Meneghini, „Il Foro di Augusto“, in: R. Meneghini u. R. S. Valenzani (Hgg.), I Fori Imperiali. Gli scavi del Comune di Roma 1991-2007, Rom, 43-60.

\section{Nash I (196I)}

E. Nash, Bildlexikon zur Topographie des antiken Rom I, Tübingen.

\section{Nash II (1962)}

E. Nash, Bildlexikon zur Topographie des antiken Rom II, Tübingen.

\section{Palombi (1997)}

D. Palombi, "Aedes deum Penatium in Velia. Note di topografia e storia“, $R M$ Io4, $435-463$.

\section{Palombi (1999)}

D. Palombi, „Penates, Aedes“, in: Steinby, E. M. (Hg.), Lexicon Topographicum Urbis Romae IV, Rom, 75-78.

\section{Papi (1999)}

E. Papi, „Romulus Divus, Templum“ („Tempio di Romolo“), in: Steinby, E.M. (Hg.), Lexicon Topographicum Urbis Romae IV, Rom, 2IO-212.

\section{Pensabene (1996)}

P. Pensabene, „Programmi decorativi e architettura del tempio di Antonino e Faustina al Foro Romano", in: L. Bacchielli u. M. Bonanno Aravantinos (Hgg.), Scritti di antichità in memoria di Sandro Stucchi. Volume 2. La Tripolitania, l'Italia et l'Occidente, Roma, 239-269. 
Platner u. Ashby (1929)

S. B. Platner u. T. Ashby, A Topographical Dictionary of Ancient Rome, Oxford.

Simon (1990)

E. Simon „Ianus“, in: LIMC V I, Düsseldorf, 618-623.

Tortorici (1975)

E. Tortorici, Castra Albana, Forma Italiae 1, 11, Rom.

\section{Tortorici (1996)}

E. Tortorici, „Ianus Geminus, Aedes“, in: Steinby, E. M. (Hg.), Lexicon Topographicum Urbis Romae III, Rom, $92 \mathrm{f}$.

\section{Welin (1953)}

E. Welin, Studien zur Topographie des Forum Romanum, Lund.

\section{Whitehead (1913)}

P. Whitehead, „Degli antichi edifici componenti la chiesa dei SS. Cosma e Damiano“, Nuovo Bulletino di Archeologia Cristiana, I43-165.

Whitehead (1927)

P. Whitehead, „The Church of SS. Cosma e Damiano in Rome“, AJA 3I, I-I8. 